University of Rhode Island

DigitalCommons@URI

Open Access Master's Theses

1970

\title{
A CAI System for Basic
}

Harry V. Aharonian Jr.

University of Rhode Island

Follow this and additional works at: https://digitalcommons.uri.edu/theses

\section{Recommended Citation}

Aharonian, Harry V. Jr., "A CAI System for Basic" (1970). Open Access Master's Theses. Paper 939.

https://digitalcommons.uri.edu/theses/939

This Thesis is brought to you for free and open access by DigitalCommons@URI. It has been accepted for inclusion in Open Access Master's Theses by an authorized administrator of DigitalCommons@URI. For more information, please contact digitalcommons-group@uri.edu. 
A CAI SYSTEM FOR BASIC

BY

HARRY V. AHARONIAN, JR.

A THESIS SUBMITTED IN PARTIAI FULFILLMENT OF THE REQUIREMIEITSS FOR THE DEGREE OF

MASTER OF SCIENCE

IN

COMPUTER SCIENCE

UNIVERSITY OF RHODE ISLAND

1970 
MASTER OF SCIENCE THESIS

Or

HARRY V. AHARONIAN, JR.

Approved:

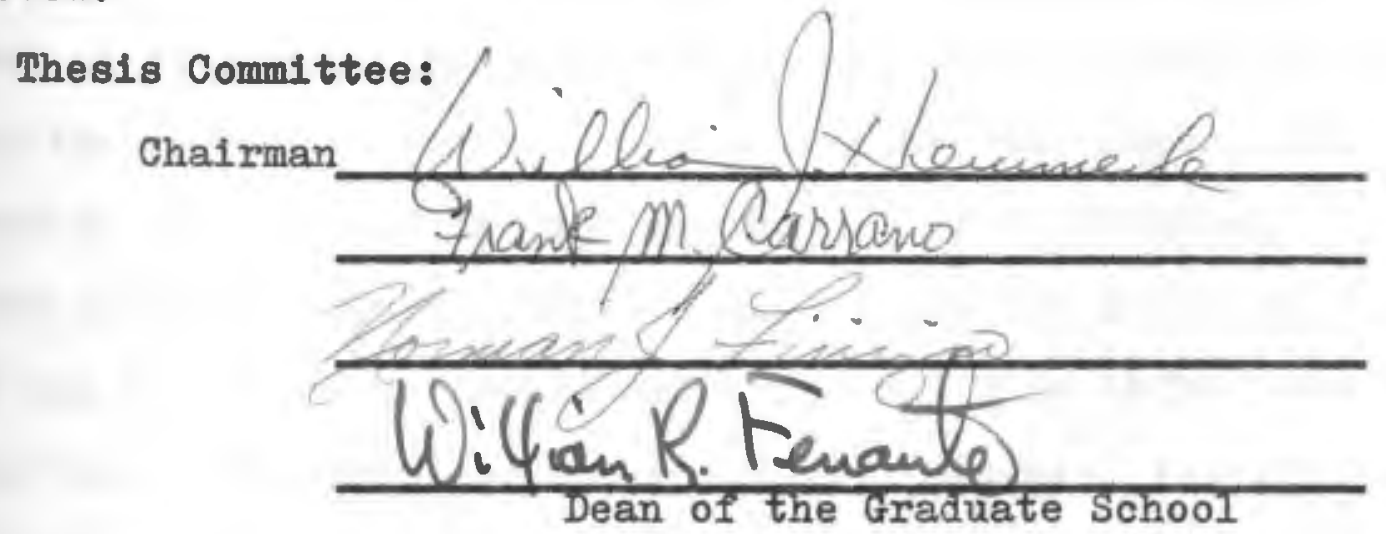

UNIVERSITY OF RHODE ISLAND

1970 


\section{ABSTRACT}

Computer-assisted instruction is a means of teaching a student by interaction with a computer through a remote console. This thesis will discuss teaching BASIC, a simple programing language, through computer-assiated instruction. The methods of instruction have been carefully planned for and tested with high school students, many of whom have had no computer programing experience.

The project involves three phases. The first phase Introduces the student to BASIC by means of a self-instructional manual contalning all the fundamentals one needs to lonow to program a falrly sophlsticated problom in BASIC. Contained in the manual are a series of questions which the student should answer to check his progress. Having finished this manual and studied the 1llustrative examples in the manual, he is now ready to be examined in this the second phese. A programmed examination is used to test each student; the questions for the exam are chosen at random from a bank of questions. The third phase involves problems atored in the computer whlch contain errors and deletions that the student must locate and correct. Th1s third phase tests the student's programing abllity, whereas, the programmed examination tests his understanding of various arpects of the language. The last two phases are more peoifically classified as computer-nanaged instruction (CIII). 
The results, after having implemented this three phase plan, were quite gratifying having used high school students from many different schools in Rhode Island. All the students were able to solve the suggested problems at the end of the olf-instructional manual which clearly indicates that the primary objective had been reached; 1.e., to teach a beginner how to program an intelligent problem in BASIC. Students also learned good programing techniques, such as conservation of storage; however, this accomplishment would be most difficult to measure as it varied from student to student. The project was also implemented in a short course for high school teachers with much the same successful results. All who participated enjoyed the CAI method of instruction. 
PABLE OP COMIETISS

Guapter

Pase

I. IHIRODUCRIOR............................ 1

II. PURPOSE OF STUDY......................... 6

III. EXPIATATIOI OF CAI SISTE $\ldots \ldots \ldots \ldots \ldots \ldots \ldots \ldots \ldots \ldots . . \ldots$

IV. BXPRRIETCES WITH CAI...................... 18

IIST OP REFEREITCES............................. 21

APPEIIIX A: IISTRUCPIOIS FOR PREPARIMO PROGRAMS

APPEADIX B: SELP INSTRUCPIOMAL MANUAL

APPEIDIX C: PROGRAMIED EXAXIMATIOH IISTIFE WITH QUESTIOTS AIT SAXPIE ERAMS

APPMIDIX D: GEIERATIHG PROGRAM FOR UISOLVED PROBLEMS WIIT ORIGITAT PROBLEMS AIID SAMPIR FXXRRCISES

APPMIDIX B: PROGRAY TO SEPARALI PREPARED UISOLVED PROBLFMIS 


\section{INTRODUCTION}

Computer-assisted instruction (CAI) is a far reaching ontity in today's computer world involving many people working on many diverse projects. For example, in a booklet titled Measibility Study and Recommended Plan for BatablishIng an Institute for Information Systens in Higher Bducation" propared by Associated Universities Inc. for the Hational Scionce Foundation ( 1 ), some 74 projects were listed in CAI ranging from "computer assisted teaching of mathematics" to "modical training simulations for anestheslologists." To define CAI would be most difficult due to the many definitions already present for 1t. Feingold in his discussion of PIAMIT, a CAI langrage ( 6 ), defines CAI in a most general way by saying it is a neans using the computer to control or monitor the presentation of some portion of information". CAI is an attempt at individualized instruction through autoation, a process emphasized in ( 3 ) as being a means of assisting the teacher" with no mention made of CAI actually roplacing the teacher. The term "CAI" 18 sometimes used loosely and may mean a number of different things. Prye, in his discussion of choosing a computer language for communication in ( 8 ), clarifies this ambigulty by outlining three major catogories that the CAI fleld may be subdivided 1nto: 
1) Problem-solving

2) Tutorial instruction

3) Computer-managed instruction

The first category, "problem solving", utilizes the computer to solve problems for a user by means of an interactive facility. "Tutorial instruction" employs the computer as a teacher, presenting the student with new material only when he has satisfactorily learned previous material. The interaction takes place between the student and computer only. When the word "CAI" is used, most often it is in reference to this particular application. Finally, "computermanaged Instruction (CMI)" deals with the computer processIng and analyzing data for the teacher with less emphasis being placed on learning directly through lessons printed at a console.

In such a learning environment, the student learns at his own rate and as mentioned in (15). the feedback to the student is almost immediate, whereas it is much longer in conventional teaching methods. Suppes in discussing some of his projects in (17), which include

1.) dr1ll-and-practice program in elementary mathemat1cs

2.) tutorial mathematics program for grade 2

3.) tutorial reading program for grade 1

4.) tutorial $\log 1 \mathrm{c}$ and algebralc programs grade日 5 to 8

mentions tests and exercises were produced for students by 
the computer, these tests being commensurable to the student's ablity. These projects involved use of remote terminals located in Californla, Mississippl, and Kentucky. Understanding the problems in education today, Suppes is quick to mention in (18) that this testing by the computer is an attempt at decreasing the burden of paperwork on the teacher. CUI is a very important aspect of CAI because its purpose is to account for the results of the examinations. In a disoussion of individualized instruction in Science ( 3 ), the authors emphasize that CMI must be able to collect and analyze the data on request in addition to storing it. It is not conomically feasible to have a computer do the job of a olerk. In this article, the "Oakleal school project" is cited as an example of a CMI type syatem. The project involved use of the University of P1ttsburgh's IBM 360 model 50 with terminals tied Into the 360 system by leased-lines. After a student finishes a unit of instruction, his performance is stored on a scratch file on disk. At the end of the day, this information is run with previously stored information - oncerning each student and an updating process takes place with the results stored back again on tape. As a result, the teacher is able to request this information regarding the progress of each student at any time.

International Business Machines (IBM) is one computer manufacturer who became involved in CAI about 1964 with the purchase of Science Research Associates Inc. In 1966, IBM thicemented the IBM 1500 CAI System. IBM has also dereloped 
a coftware package called "COURSEWRITER", a language sultable to their CAI needs (4). Studies have since been made by IBM at Iorktown Heights, New York using the IBM 7010 ( 5 ). Ioday, IBM is st1ll involved in CAI. For example, the Oniversity of Rhode Island Computer Iraboratory recently inatalled an IBM 2314 disk drive. The IBM customer engineer assigned to the University attended a school to learn about the IBM 2314. The method of instruction was CAI. The engineer worked atrictly with remote terminals spending approximately 32 hours on the course, working at his own rate. To save time at the terminal, he was issued a manual to read Instead of having the terminal reproduce the manual for him, a very time consuming and costly operation.

The University of IIlinois has developed the PLATO system mentioned in ( 5 ). The system primarily involves the simulation of a classroom. PJATO is used both as an instructional tool (OAI) and a data processing tool (OMI). CurrentIy, there are criticisms of CAI involving 1ts high cost. Iet, Professor Bitzer, Director of the Computer-Based Education Research Iaboratory at the University of Illinois, claims in the $1970^{\prime} \mathrm{s}$, PIATO w1ll cost approximately $27 \%$ per student hour ( 2 ). It should be noted that, as mentioned in (1), the cost of computers is decreasing, whereas the cost of humans is increasing.

The study of forelgn languages is another area of interest in CAI. Suppes feels the otudy of foreign languages through CAI is Important and comments on the fact in (17) 
that Russian is usually more difficult for Americans to learn than German, French, or Spanish. He concludes that individualized instruction would be an attempt at correcting this. Other computer manufacturers have become interested in CAI. Goneral Electric is one manufacturer making use of toletypewriters (10). In their Iibrary of programs related to foreign language CAI programs, are the following which deal with Irench $(9)$ :

FRPROGI Produces questions at random FRPROG2 Questions sequent1ally FRVOC-1 Vocabulaxy arill in French FRVARB-1 Verb drills in French

The complete list of projects and participants in CAI is much too loug to mention here; however, a great deal of work at1ll needs to be explored. Some CAI researchers feel that CAI can not thrive on research alone but must be implemented and tested in a real-world environment. It is the oplation of Kanner in (13) that "there should also be the recognition that farorable research results are only a prelininary to many long jears of adaptation and acceptance wthin current edicational practices." 


\section{PURPOSE OF STUDY}

The purpose of this study is to teach through computerassisted instruction the programming language BASIC, an interactive computing language developed at Dartmouth University by Professors John G. Kemeny and Thomas F. Kurtz for the GE-265 TSS (time-sharing syotem) (7) (8). The anthors note that the name "BASIC" (Beginner's All-purpose symbolic Instruction Code) is a misnomer because it is being used by experts as well as novices. BASIC is relatively casy to learn as proven by Kemeny and Kurtz who at Dartmouth taught the Ireshman class how to program BASIC in two one-hour lectures (14).

In order to best accomplish the purpose of this study, a complete CAI system was deslgmed with the use of the components of a CAI system mentioned in Chapter I. The format for the aystem calls for a three phase plan. The initial phase involves the student reading a self-instructional manual discussing the 1deas and concepts of BASIC. The manual 1s dealgned to have questions after most sections to insure the understanding of the reader. This technique is analagous to the objectives of "tatorial instruction" mentioned in Chapter I. The purpose of the manual is not to have the remote terminal produce a manual for each student. The reasons being that the time spent on typing the manual 
is great and the cost of computer time is rather high. At the conclusion of the manual are suggested problems for the student to try his problem-solving ability.

The second and third phases of the CAI system involve tosting and recording student data by means of CMI. The socond phase is a programmed examination covering material one needs to know in order to program in BASIC, whereas, the third phase has the student complete a program which is presented to him with errors and deletions. These two phases can be employed off-line as well as on-line.

For phase two, questions are chosen at random from a bank of questions whlch were supplied as data. The number of questions to be asked on the exam is a variable parameter which can be controlled by whoever is preparing the examinat1ons. Once the student makes a response and enters 1t, it is checked and, if correct, another question is presented. If on the first try an incorrect response is made, a second answer 1s allowed; however, if the correct answer has not been given after the second try, the correct answer 1s then given. At the end of the examination, a summary is given as to the number of questions answered correctly the first time, the number answered correctly the second time, and Iinally, those questions to which the correct answer had to be given. 1 roplcienoy rating follows as to whether the student performed "excellent", "good", "falr", or "poor". Thus, the exams are graded for the teacher. A routine is incorporated to 
provide the teacher with information about how each question In the library was answered.

The final phase of the CAI project is to have the student "debug" programs presented to him on the remote console. He is to examine the coding (either on-line or off-line) and declde what changes need to be made. There are various types of changes the student must make. These changes are described in the next chapter. Once the changes are made, the student oheoks his work by running the corrected program and examining the results. It is very possible that he must make further corrections due to his having missed an error or due to one of his corrections being incorrect. There are a number of these programs which may be prepared with varying complexity. (See Appendix A).

This three phase project not only teaches a beginner BASIC but tests his proficiency in it by examination and program "debugging" with the results passed along to the teacher. The routine that records the responses for each question is of great help to the teacher who prepared the questions. A question answered incorrectly all the time may be too difficult or worded incorrectly. Similarly,

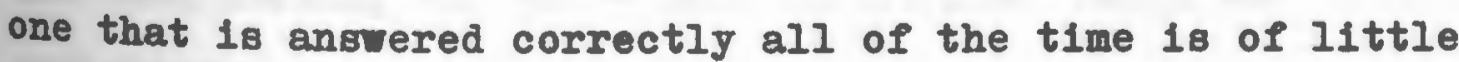
value. 


\section{EXPLANATIOII OF GAI SYSTPBM}

The self-instructional manual entitled, "Self Inotruction for BASIC Programing" was written primarily for the fruior and senfor high school student wanting to learn the elementary ldeas and concepts of a relatively imple programing language. The format of the manual provides for questions at the conolusion of most sections in order to check the understanding of the reader. Following the questions are a list of answers and explanations to these questions. This manner of teaching is similar In purpose although different in format to (11), (12), and (16).

Ohapter I deals with symbols, constants, and variables. The symbols discussed are both the equality and inequality aymbols as well as all the arithmetic symbols that the BASIC aystem uses. The section dealing with constants describes what the BASIC system recogaizes as a valid number. sinilarly, the section on variables deseribes rules to follow when forming variables and illustrates valid and invalid variables.

Chapter II deals entirely with statements, 1.e., commands which one can use in BASIC. Beginning with the format of a statement, each statement is handléd in its own section with questions appearing after most sections. The question- 
Ing appect is very crucial since material discussed in one sootion may depend on material appearing in a previous sect10n. Simple problems are coded for illustration purposes. Having oompleted this chapter, the student should be able to Inderstand and use the BASIC commands.

Ohapter III Ilsts the arithmetic and trigonometric functions which are arailable to the BASIC user. These include sine, cosine, and tangent of an angle, as well as square root, absolute value, and sigm of a number. These functions are 1llustrated in sample programs.

Ohapter IV contains five problems which again were chosen so as not to present much difficulty to the reader. Following a description of the problem is the solution programmed in BASIC as a student might solve 1t. This is not the only solution!

For completeness, Appendices A and B of the selfinstructional manual contain a list of matrix operationa available and suggested problems, respectively. The matrix porations are not discussed since most students at this level are not familiar with matrices.

The second phase is a programmed examination which jwesently chooses ten questions at random from a bank of lorty questions. Both these parameters may be altered if dosired. Each question has a corresponding solution statement which may or may not hare to be supplied to the student and a list of possible answers for each question. These ancwers are presented in multiple cholce form. A key is 
also wplied with the question indicating where the corroct solutions 110. Fach examination generates a random kej In addition to choosing questions at random. For example, the answer to the question chosen to be the fifth question may be number one.

\section{WHICH IS THE CONVERSATIONAL READ STATEMEMT IN BASIC}
1) IIPUT
2) DATA
3) READ
4)PRIII

If the random key does not indicate the solution for quation five to be a "one", then the correct response is moved to the prescrlbed location by exchanging cholces. If the random key chooses number "three", then the question will appear as follows:

\section{WHICH IS THE COMVERSATIONAI READ STAPEMENT IN BASIC}
1)READ
2) DATA
3) INPUT
4)PRINT

Should the fourth choice be "none of these", It is never moved from this fourth position.

After each quest10n, the student enters the response nI, 2, 3, or $4^{\mathrm{H}}$ corresponding to $\mathrm{hls}$ cholce. If any other cheracter 18 entered, a message will appear indicating only a $91,2,3$, or $4^{\prime \prime}$ is a valid response. If the cholce 18 correct, the next question w1ll appear; otherwise, the student 18 allowed a second try. This second try may not be the same response given the first time for the program checks to make sure two separate cholces are made. If the second cholce is also incorrect, the correct answer to the question will appear. 
A summary is given at the end of the examination indicating how many questions were answered correctly the first time, how many the second time, and how many were answered recessfully. A record is kept as to how each question was cnowered, allowing the instructor to view the data at his request and evaluate the questions in the examination. Following the summary is a proficlency rating indicating how well the student performed.

Should a student desire to repeat the examination, ten guestions will again be chosen at random along with a new key. It is likely that a question or questions may appear that the student has already seen but, he will probably find the correct answer to be another choice. Bxpanding the bank of forty questions would lessen the chances of reoccurrence of questions.

The third and final phase is to have the student attempt to correct a given program which has a variable number of orrors and deletions in 1t. The programs chosen are not very diflcult, and involve basically the same ldeas as the problems the student tried in Appendix B of the self-instructional manual. Appendix A outlines the method for preparing these problems.

The BASIC statements are classified as follows:

$\begin{array}{lllll}\text { CIASS I } & \text { IEW } & \text { GOTO } & \text { IF } & \text { PRINT } \\ \text { CLASS II } & \text { FOR } & \text { NEXT } & \text { READ } & \text { DIM } \\ \text { CIASS III } & \text { DATA } & \text { IIPUT } & & \end{array}$


The types of deletions which may occur are:

TIPE I ENTIRE IIIS IS DELETED

PYPE II ALC IIPORMATIOI EXCRPI BEY WORD IS DELETED

TIPI III KET WORD IN IIINE IS DELETED

Fresently six programs exist and are prepared simultanoously with the following input paraneters arailable to the user preparing the programs. These paraneters allow one to vary the complexity of the problems.

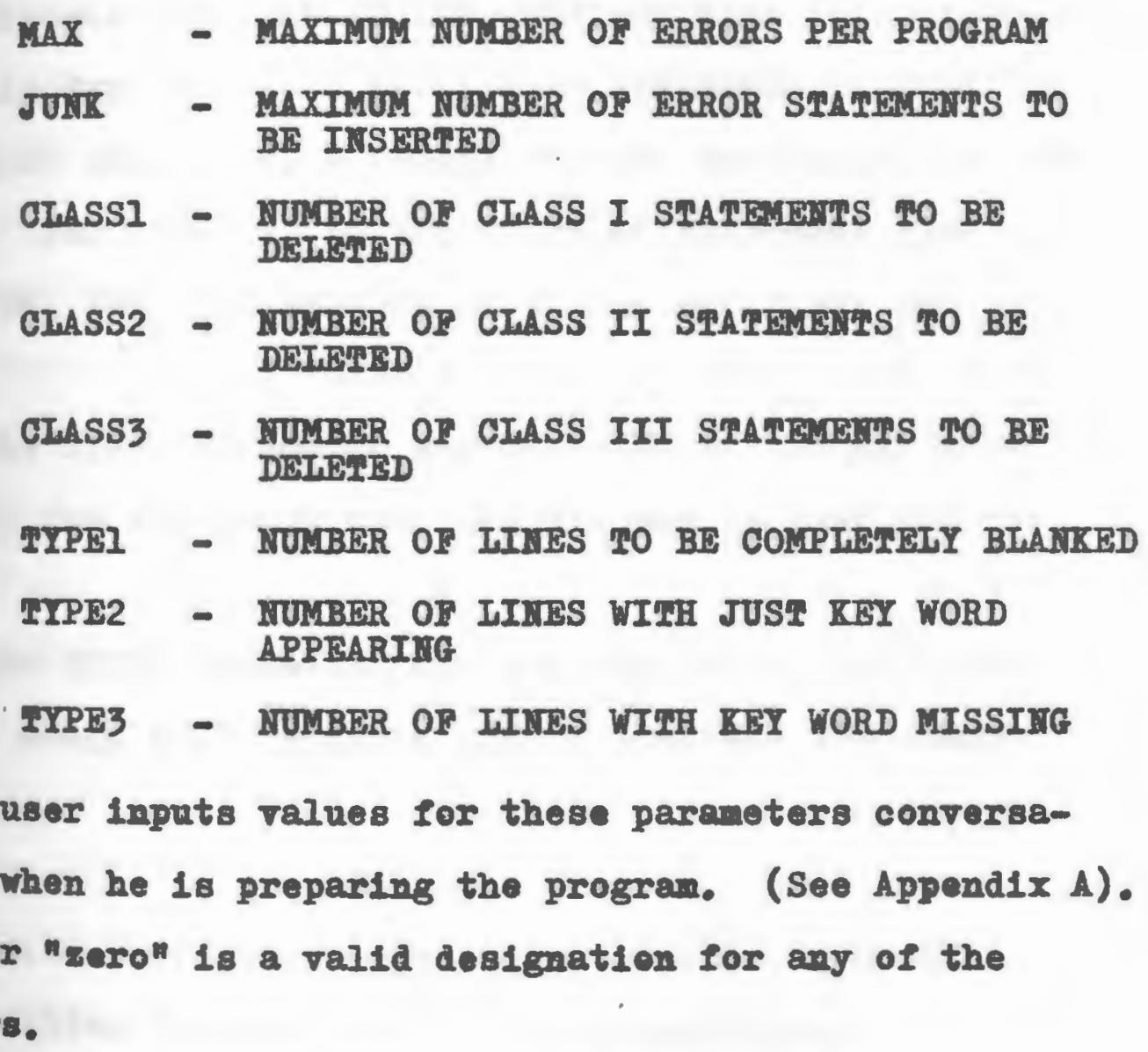

Class III statements are handled f1rot. The parameter "Clase3" causes a random process to begin whereby as many 
Class III tatements are generated as specified by the Turlable Mclass3". Each of the Class III statements generated are scanned for in each of the six programs sequentially. When the particular statement is encountered, the entire line 18 blanked, 1.e., TYPII change. All Class III statements are coupletely blanked out this way.

Class II statements are considered next. As was the case for Class III, randomly, statements of Class II are generated. Each program is scanned for the Class II statement at hand and the changes made are in the order of Type III, Type II, and finally Type I. If a partloular statement acanned for appears more than once, a random process is employed to select one. For example, if the Class II statement generated were "RGAD", the statement found in a program may be:

\section{READ N}

If the TYPE3 parameter was not sero or had not been crhansted, the statement would be changed to look like: 12 N

If the TYPE3 parameter was not avallable, the TIPE2 parameter would be considered and if possible the change vould bes

\section{READ}

If nelther of these types are avallable, the entire Ine 18 omitted leaving just the statement number:

Class I statements are considered last and are handled exactly the same as Class II statements. 
Ifter the three classes of statements have been 1nHonented according to the speoifled type changes, the maxiInum orsor per progran paranoter nay not be sat1afled in all pregrans. Incorporated as data to the master program 18 a 11st of BASIC statemente whlch are correct but 11 inserted In any of the alx programs will canse errors to occur if uncotocted. The Iinal paraneter to be discussed 18 one indicatIng the number of these lines to be inserted in the proparation of the alx programs.

If the number of irrelevant statements to be inserted 18 four, then four randon numbers are generated between one and alx, each represonting one of the problems. If the randon numbers generated were "1, 6, 2, 1," this would meen program "one" w1ll get two lines replaced 19 poselble and program "two" and "six", one each if posalble. Otherwise, no zoplacement takes place.

It may be that just program "glx" has not reached the narimum change parameter. If so, one line is chosen at random Irom the data and all the statements like this one in program "glx" are consldered likely candidates to be replecod. If the statement chosen was a "Gomo" statement, program alx may contain three "goron statenents. One is chosen at random and replaced by the new ncopon. G010 17 (GOTO chosen from list of statenents randomly)

$\left.\begin{array}{ll}\text { GOYO } & 12 \\ \text { GOYO } & 19 \\ \text { GOYO } & 24\end{array}\right\}$ All located in program six

GOMO 24 Chosen as one to be replaced by GOMO 17 
How statenent "GOTO 24" is repleeed by "GOTO 17" thus cussing an improper branch. All lines inserted causing orrors are handled this way.

Inally, a check 1s made to see if the six programs have reached their maximum number of changes. If not, a scan 18 made for "IF" and "POR" statements in these programs where another change can be made. The equality/inequality arbol 1s remored from the "IF" statement and the starting, onding, and Inerementing values from the "FOR" statement. For example:

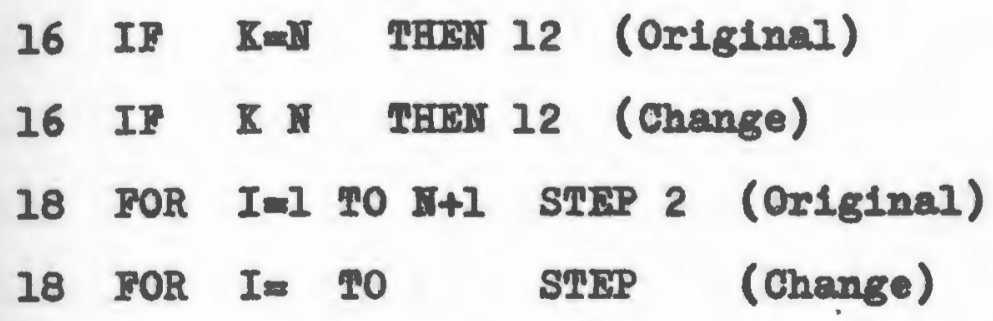

If at any time there is more than one candidate for a change in one program, one will be chosen at random. Suppose an "IP" statement is chosen as an irrelevant statement to be inserted into program five. If progran five has not reached the marimum number of changes, it is possible that this ine will become part of program five and furthermore, the equality/ Lrequality symbol stripped off.

\begin{tabular}{|c|c|c|c|c|}
\hline 15 & IF & $I+I<\mathbf{K}$ & THFN 20 & (Original "IP" statement) \\
\hline & IF & $I<=K$ & THEN 18 & $\begin{array}{l}\text { ("IF" chosen to be inserted } \\
\text { replacing above) }\end{array}$ \\
\hline & If & $I<=K$ & THEN 18 & (Hew IIne 15) \\
\hline & IF & I $\mathbf{K}$ & THEस 18 & $\begin{array}{r}\text { (Program allows "IF" to be } \\
\text { altered) }\end{array}$ \\
\hline
\end{tabular}


Iote that the number of spaces constituting a blank do not nocossarily indicate the number of character missing. creat pains have been taken to insure that rariables in these Iine insertion statements appear in all six programs, thus making their detection more challenging.

Th1s third phase tests the student's understanding of a problem and its solution in BASIC. The problens, simple in nature, can be made vory challenging. 
IV. GXPRRIBHCES WITH CAI

For ten weeks during the summer of 1969, this author hed the opportunity to work with high school students from all parts of Rhode Island, teaching them FASY (Blementary Lasembler and Machine Systen) and FORTRAN IV. ThIs program was part of the National Sclence Foundation's Cooperative college-School Sclence program. Support for this high wohool program was through a llational Sclence Poundation cant (GN-4150) and the University of Rhode Island Computer Inboratory. Most students were beginners having had no prevlous computer science background whlle others had a semester course in programing at their respective high sohools. Wuch insight was gained into the capability of today's high school strdent and what type of mathematical training he has. It was interesting to note that the beginners did almost as well as others with some experience since the course was taught at the beginner's level. This is not to say that those with experience were bored; rather, they were able to add to their previous knowledge. The awareness of these atudents and their high retention rate was also obcerred. It was these observations which led to the developaent of this CAI system of teaching BASIC to high school otredents.

Buring the spring semester of the 1969-70 school year, 
the University of Rhode Island Computer Iaboratory and the Cationel science Foundation grant (GW-5lll) provided funds for a short course to high school teachers. These short courses were taught at South Kingstown, M1ddletow, and Jutgmouth High Schools, one hour a week for four weeks The text used in the course was the self-instructional manmal of this project. Host teachers were able to write procrams by the second week. In theix attempts to learn BASIC, they provided excellent criticisms of the manual which they were using. These helpful criticisms led to a later revision of the manual. The courses were successful since those oompleting it were able to program fairly well by the end of the lourth week.

Another workshop for high school students was offered again during the sumer of 1970 sponsored by the latest Jational Science Foundation grant and University of Rhode Island Computer Iaboratory. The students in this program were given an opportunity to use the entire CAI gystem to learn BASIC. Due to a time factor, the teachers participating in the short courses were only exposed to the selftutructional manual.

The students were allowed one day to read the manual. Once they finished and their questions answered, they were asigned the elght problems in Appendix B of the manual. The colutions to these problems raised more questions from the trudeats and those questions were also resolved. How, having done some programming, the students were ready for the second and third phases of the system. 
The pregramed examinations, as well as the unsolred poblens, wore a challenge to many. It was intereating to Ilew the atudents who were beling teated in a new way. Crit1of 8 en drawn from the class at the ond of the program Indicated that they were very much in faror of being taught by a selftructional manual and tested at a remote terminal. This ClI project added to the success of the workshop whose prime ojective was to teach BASIC. ThIs objective was more than not. 


\section{IIST OF REFERENCES}

1. Insoelated Universities, Inc. "Feasibillty Study and Recommended Plan for Ratablishing an Institute for Information Systems in Higher Bducation." Prepared for National Sclence Foundation. Washlngton, D.C., June 1, 1969.

2. Bitzer, Donald I. A Large Scale Computer-Based Education System with Demonstration centers, computerBased kducation Research Laboratory, University of Illino18, Urbana, Illino1s, November 13, 1967. 3. Cooley, William W. and Glaser, Robert. "The Computer October, 1969, pp. 574-582.

4. COURSEWRITER. Computer-Assisted Instruction, IBM Research Reports, Vol. 2, ijo. 1, January, 1966, Thomas J. Watson Research Center, Yorktown Heights, New York.

5. Crowell, Fred A. and Traede, S. Carl. WThe Role of Computers in Instructional Systems: Past and Future." Proceedings of 22nd Hational Conference, Association for Computing Machinery, 1967.

6. Joingold, Samuel I. "PIAAIIT - 1 Language for CAI," Datamation, September, 1968, pp. 41-47.

7. Frye, Charles H. "CAI Languages: Capabilities and Applications," Datamation, September, 1968, pp. 34-37.

8. Prye, Charles H. "Choosing a Computer Language." The Use of Computers in Secondary School Mathematics. Edited by Dudley I. Post. Newburyport, Mass: Pntelek, 1970.

9. Goneral Electric Information Service Department. "Rducat." Catalog of Educational Time-Sharing Programs. December, 1969.

10. Coneral Electric Information Service Department. "Program Library." Mark I Time-Sharing Service General Catalog, October, 1969. 
11. Hoaly, Jeremiah J. and DeBruzz1, Delward J. Basie FORIRAN IV PROGRAMITIG. Reading, Mass, : Idd1sonresley Publishing company, 1968.

12. Wternational Business Machines Corporation. coding an Introduction to PI/I Text." First Edition, 1967.

13. Kanner, Joseph H. "CAI - The Hew DemonologJ?" Detanetion, September, 1968, pp. 38-40.

14. Kemeny, John G. and Kurtz, Thomas E. "The Dartmouth IIme-Sharing Computing System." Course Content Improvement Program. Iational Science Poundation, (Grant ISF - GE-3864). PInal Report, June, 1967.

15. ThoDonald-Ross, Michael. Programed Learning - A Decade of Development." International Journal of ManYachine studies, I (January, 1969), pp. 13-100.

16. Spitzbarth, Iraurel H. Basic COBOL Programming. Reading, Mass.: Addison-Wesley Publishing Company, 1970.

17. Suppes, Patrick. "Computer-Assisted Instruction: An Orerview of Operations and Problems." Invited paper at IFIP Congress 68, Hdinburgh, August, 1968.

18. Suppes, Patrick. "Computer Pechnology and the Future of rducation." Computer-Assisted Instruction. Fd1ted by Richard C. Aticingon and H. A. Wilson. New Iork: Academic Press, 1969. 


\section{APPENDIX A}

IISTRUCTIOIS FOR PREPARIIT PROGRAMS 


\title{
LPPEIDIX A: INSTRUCTIONS FOR PREPARING PROGRAMS
}

In order to prepare an examination for a student, all one needs to do under the University of Rhode Island Computer inboratory RAX System is to include the name "BASICX" in an leput file and run this file in the following manner. Type In the commands

\author{
/INPOT \\ /ITCLUDE BASICX \\ /IIISERT KEEP \\ /MID
}

After the system types "BBGIN ACTIVITY", type /PURGE KEEP (LOCK CODE)

where the "IOCK CODE" 1s a four digit number designated for each user of the system. The file NKEEP" 1 s purged so that a new one can be saved after the examination. Inftially Input a flle "KKEEP" of forty blank lines. Th1s file is for woounting purposes so as to keep track of how students respond to each question.

Lfter the "BEGIN ACTIVITY" message, type

\section{/ROR}

Now the directions for the exam will be typed out on the censole. Bach of the ten questions will be typed out with their appropriate cholces. When a question is asked, an merline character is typed out indicating the keyboard is 
mocked and the student may enter his choice for this floular question (see Appendix C). After the examinat10n, the message "BEGIN ACTIVITY" Will appear again. Type /SAVE TCEEP(IOCK CODE), ST

In order to save the file of question responses.

The programmed problems appear in the system solved correotly under the file name of "ORGPGSn.(original programs). Jresently, there are six different problems in this ille. The program which causes changes to occur in these programs is called "PREP" (see Appendix D). Thus to prepare the six problems, type

\section{/INPUT \\ /IITCIUDE PREP \\ /INCLUDE ORGPGS \\ /HID RON}

Now the user must supply various paremeters by means of the console on request. The parameters include maximum number of errors per program, number of irrelevant I1nes to be Inserted in the preparation of the programs (both I2 formats), number of each class of statements to be changed ( 3 I2 format), and the number of each type of change (3I2 format). When "BEGIN ACTIVITY" appears, save the prepared work which is on a work file in some file of your choosing (mggest ATISEY). To separate this file which contains all oix programs joined together, call a program "SIICE" which will take each file and save it on a work flle for the user to save under an appropriate name (see Appendix E). 
The user must supply the firat ard last 11ne numbers of the 110 he 18 extracting. Typo

$$
\begin{aligned}
& \text { /IIPUI } \\
& \text { /IECLUDE SIICE } \\
& \text { /IRCLUDS ALTSET } \\
& \text { /HID RUI }
\end{aligned}
$$

after which w11l appear an underline symbol allowing the user to type in the two Iimits (both I3 format). Repeat this precess for each of the $1 x$ prograns $t 111$ each is saved under 1ts own name. 
APPENDIX B

SIIP IISPRUCYIOMAT MAXTAT 


\section{SELF IISTRUCTION}

\section{POR}

\section{BASIC}

\section{PROGRAMMING}

BARRI V. AHAROHIAH, JR.

REVISED EDIPION JUNE 1970 


\section{Preface}

This text is designed to teach a beginning programmer the basic concepts and ideas of the programing language BASIC (Boginner's All-purpose Symbolle Instruction Code). A relatirely new language, BASIC was designed by Professors John $\theta$. Iemeny and Thomas F. Kurtz of Dartmouth Oniveraity for application to computing environments supporting remote consoles. The propose of this manual is to instruct one interested in programing the basic principles and statements of the BASIC language needed to solve a problem via progranming methods.

In addition to this text, there is avallable programed examinations to test the kowledge of the student. Questions for the examination are chosen at randon to insure different exams for each student. Once the exam is completed, a report is given Indicating how well the student performed. Information concerning examinations may be obtained through the author of this manual. 


\section{TABIE OF CONTENTS}

\section{Page}

\section{CEAPIER I Symbols/Constants/Tariables}

1.1 symbols......................... I

1.2 Constants........................... 3

1.3 Variables........................... 4 CHAPIER 2 Statements

2.1 statements......................... 6

2.2 READ............................. 7

2.3 DATA............................. 7

2.4 RESTORE............................ 8

2.5 PRIXT............................. 9

$2.6 \operatorname{IET} \ldots \ldots \ldots \ldots \ldots \ldots \ldots \ldots \ldots \ldots \ldots \ldots \ldots \ldots \ldots \ldots \ldots \ldots \ldots . \ldots 11$

2.7 GOTO............................ 13

2.8 IF................................ 13

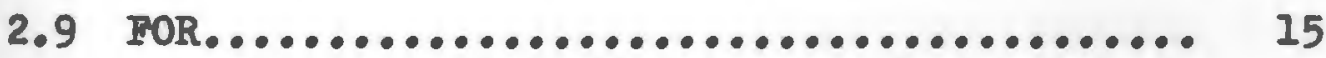

$2.10 \operatorname{NEXT} \ldots \ldots \ldots \ldots \ldots \ldots \ldots \ldots \ldots \ldots \ldots \ldots \ldots \ldots \ldots \ldots \ldots \ldots$

2.11 FND................................ 17

2.12 INPUT.............................. 18

2.13 DEF............................... 20

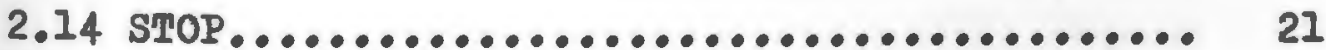

2.15 RBM................................. 22

$2.16 \mathrm{DIM} \ldots \ldots \ldots \ldots \ldots \ldots \ldots \ldots \ldots \ldots \ldots \ldots \ldots \ldots \ldots \ldots \ldots . \ldots \ldots \ldots$

2.17 GOSUB............................... 23

2.18 RWIUR................................ 23 
Page

OLAPTTR 3 Functions

3.1 Bullt-In Functions....................... 24

3.2 Numeric Applications................... 25 GPLPTER 4 Problems and Solutions

4.1 Square Root Problem..................... 26

4.2 Prime Nrumber Problem..................... 27

4.3 Area-Perimeter Problem.................... 28

4.4 Buclid's Algorithm........................ 29

4.5 Sort Problem........................... 31

APPENDIX A Matrix Operations..................... 33

APPENIX B Suggested Problems..................... 34 


\section{1,1 Srmbols}

The language BASIC offers very little change to the common notation used in elementary mathematics to express relationships between numbers. The lirst type of symbols we will mention deals with equality and inequality. The symbols, their meaning, and usage are summed up in Table 1.

\begin{tabular}{|c|c|c|c|}
\hline Srmbol & Meaning & Example & Puxpose \\
\hline$=$ & equals & $A=B$ & A equals value of $B$ \\
\hline$<$ & less than & $\mathbf{A}<\mathbf{B}$ & A is less than B \\
\hline$>$ & greater than & $A>B$ & A is greater than B \\
\hline 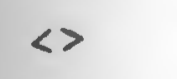 & not equal to & $\mathbf{A}<>\mathbf{B}$ & $A$ is not equal to $B$ \\
\hline$<=$ & less than or equal to & $\mathbf{A}<=\mathrm{B}$ & $\begin{array}{l}\text { 1 is less than or } \\
\text { equal to } B\end{array}$ \\
\hline$>=$ & $\begin{array}{l}\text { greater than or } \\
\text { equal to }\end{array}$ & $A>=B$ & $\begin{array}{l}\text { A is greater than or } \\
\text { equal to B }\end{array}$ \\
\hline
\end{tabular}

Table 1. Equality/Inequality Symbols

In addition to the equality and inequality symbols, we have arithmetic symbols. These symbols are used to denote arithmetic operations. Several symbols may be combined to form an expression in BASIC.

Srmbol Meaning

+ addition

- subtraction

* multiplication

/ division

exponentiation

\section{Frample Purpose}

$\mathbf{A}+\mathbf{B}$

$\mathbf{A}-\mathbf{B}$

$\mathbf{A}$ *B

A/B

Al B add $A$ and $B$

subtract B from A

maltiply $A$ by $B$

divide $A$ by $B$

ralse A to the power $B$

Table 2. Arithmetic Symbola 
untions from Section 1.1

Irue - False

1. One indicates Inequality in BASIC by $n+m$.

2. Bxponentiation utilizes the "/" character.

3. BASIC allows more than one arithmetic symbol in one expression.

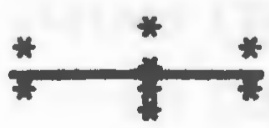

\section{Brolanation}

1. Palse. Inequality may be teated only by the " $<>n$ symbols.

2. False, Bxponentiation may only be indiceted by a $n / n$.

3. True. This form is allowable; for example, to add three variables we have: $A+B+C$

Iote: Operations are performed with the following priorities

1. Breluate expressions in parenthesis

2. Ixponentiation

3. Nultiplication and Division

4. Mddition and Subtraction 


\title{
1.2 Constants
}

Constants may contain from one to nine digits with a decimal point if needed. Only the digits $0,1,2,3,4,5,6,7$, 8, 9 may be used. Bxamples of valid and invalid constants are given in Table 3

\author{
763 (VAIID) \\ 947.2 (VAIID) \\ 216347889 (VATID) \\ $15 \times 10$ (INVAIID) \\ 6.3 .2 (INVALID) \\ 1134482006 (INVAIID) \\ Table 3. Constants
}

\section{Qpestions}

Indicate which of the following are valda constants. If invalid give reason.

a. 2001

b. $9.80 * * 2$

c. 19.86727649

d. .89999

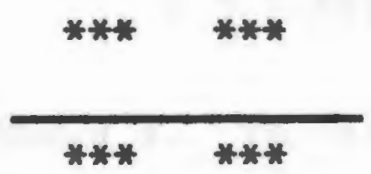

\section{ionlanation}

a. VAIID

b. IWVAIID since asterisks are not allowed.

c. INVAIID because of too many characters.

d. VAIID 


\title{
1.3 Variables
}

In elementary BASIC as in many programing langrages, variables are used to represent values we store in the computer for later calculations. If, for example, we wanted to oompute the area of a circle, we would need to know the radius or diameter to whlch we would asalgn a name to hold the value. In 11 ght of the fact that this radins or diameter will vary for different circles, we have the term "variable name". To create a valid variable name, we aimply use a letter of the aphabet or a letter immediately followed by a digit from 0 - 9. Thus in any program, there is a total of 286 possible variable names. There is another class of variables to which we may assign a subscript called "subscripted variables" (Section 2.16). Table 4 illustrates some valid and invalid variables.

\author{
S (TAIID) \\ K7 (VATID) \\ XT (IMVAIID) \\ 7B (INVAIID) \\ X33 (INVAIID)
}

Table 4. Variables 
enestions from Section 1,3

Indicate which of the following variable names are valid and invalid. If invalid, give reason.

a. D4

b. $\mathrm{z}$

c. 49

d. JI

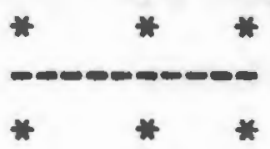

Explanation

a. VATID

b. VALID

c. VAIID

d. INVAIID since I is not a digit. 


\subsection{Statements}

Statements in BASIC are instructions which direct the computer to execute varions computations. For our purpose, we shall study seventeen types of BASIC statements wich will provide a great deal of flexibility in solving joblems. There is one inportant fact that 18 common to all BASIC statements and that is each must have a statement number which must not exceed four digits. As we study each statement, you w1ll find the statement number always appearing ilrst. Most statements are referred to as "executable" statements; however, statements such as "FND" and "DIM" are not executable.

\section{Questions}

1. Classify BASIC atatements into two general oategories.

2. What do statements cons1st of?

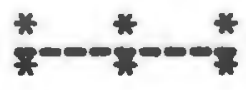

\section{Brplanations}

1. Brecutable and non-executable

2. Statement number, symbols, numbers and variables. 


\subsection{READ}

The READ statement is used for inputting values into the computer. The values that are to be read in are assigned to variable names, these values coming from DATL statements (Section 2.3). Following the statement number, we have the word READ and a list of variables or perhaps just one variable whlch seek values for later computations. The variables are separated by cormas.

\section{$116 \mathrm{RBAD}$ H \\ 124 READ H8, G, I, T6}

\subsection{DATA}

The DATA statements form a block of information which is referenced by the READ statements. The data block is a list of ralues to be assigned to variables located in READ statements. This list of ralues is stored in the machine. The "data block" is oreated this way; whenever a DATA statement 1s oncountered, the values on the DAPA statement are added to the list of values from previous DATA statements. The ralues are also separated by commas.

$$
170 \text { DATA } 23.6,42,16.1
$$

"Data block" looks like $\begin{aligned} & 23.6 \\ & 42 \\ & 16.1\end{aligned}$

171 DATA $43.7,5000$

$\begin{array}{cl} & 23.6 \\ 42 & \\ 16.1 \\ 43.7 \\ 5000 \\ \end{array}$


These two statements illustrate the assigament of the ralue 7 to the variable $X 2$ and the value 2 to the variable $J$. Bramine the following:

$$
\begin{aligned}
& 100 \text { RFAD A,B,C } \\
& 150 \text { RFAD } \mathrm{X}, \mathbf{I}, \mathbf{Z} \\
& 180 \text { RFAD J } \\
& 200 \text { DAFA } 20,30 \\
& 206 \text { DATA } 3,6,9 \\
& 208 \text { DATA } 11,12
\end{aligned}
$$

Once the machine examines these instructions, we have the following:

$$
\begin{aligned}
& A=20 \\
& B=30 \\
& C=3 \\
& X=6 \\
& Y=9 \\
& Z=11 \\
& J=12
\end{aligned}
$$

$\Lambda$ better way to write this would be:

$$
\begin{aligned}
& 100 \text { READ } 4, B, C, X, Y, Z, J \\
& 200 \text { DATA } 20,30,3,6,9,11,12
\end{aligned}
$$

\subsection{RESTORE}

Whenever a READ statement is encountered, the value inadiately following the last ralue read in is now read. To roturn to the beginning of the list of ralues assigned to this data 1lst, the programer simply inserts a RESTORE command. 
For example, if the data block consisted of the following values

and if the first two values had already been read, then the next variable in a READ statement would be assigned the value "3". If, however, a RBSTORE command were executed, the value assigned to the variable in the next READ statement would be "4" instead of "3n.

\subsection{PRINT}

The PRINT statement is used to print out remarks and ralues assigned to variables. To print out the answer to a given problem whose solution is stored in $X$, one may code the following:

\section{PRINT "ANSWER IS" \\ 130 PRINT X}

Hotice that remarks are printed by simply enclosing in quotation marks the desired characters. This same example may be coded

\section{PRINT "ANSWER IS", $X$}

The comma provides long spacing between the remark and the value of $\mathrm{x}$. Short spacing is accomplished by replacing the comma by a semicolon. The primary difference between the above examples is that the value of $X$ will be printed below the remark in the first example and next to the remark in the second example. Short spacing simply means that the arguments 
In the PRINT statement are printed closer together. Similar1y, long spacing provides wider spacing on the printed line of the arguments in the PRINT statement.

\section{Questions}

1. Can we use a READ statement without having defined a data block?

2. What value will be printed out after the followIng instructions are executed?

161 READ $1, B 1, D, G 9, \mathrm{~K}, \mathrm{I2}$

162 DATA $6.35,900,42.0,8.0$

163 PRINT Y2

164 DATA $82.9,0.1,62,7,0$

\section{Bxolenations}

1. No. The READ statement takes the values in the data block and essigns them to variables.

2. The value of only Y2 18 printed. Since the data block consists of $6.35,900,42.0,8.0,82.9,0.1$, 62, 7 and 0 , we observe that the sixth value is being assigned to $12,1 . e ., 0.1$. 


\subsection{IIJT}

The IFI statement is used to assign values to variables, or to compute values and then asalgn the result to variables. IET variable = expression

Bramples:

100 IEP $A=10$ (assigns value 10 to variable 4 )

120 IET $G=a+1$ (increments value of $G$ by one)

140 IFW $M=B+C$ (assigns $M$ the sum of $B$ and $C$ )

Note that the second example does not appear to be athematically correct. The equal sign should be interpreted as "Is replaced by" and not "1s equal to". The variable G is increased by 1 and this result replaces the previous ralue of $G$.

The BASIC language assumes that any variable not previously defined has a value of "zero". Thus the programmer may inftialize a variable to contain a "zero" by

$$
\operatorname{LET}(\operatorname{varlable})=0
$$

or completely omit this statement in which case the variable will be nzeron. 


\section{prestion}

Determine what value is printed after execution of the sollowing:

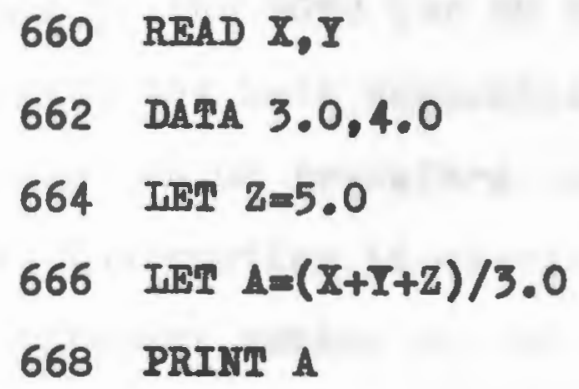

\section{Frolanation}

Inttially the variables $X$ and $I$ are 3.0 and 4.0 respectIvely. The varlable $Z$ is assigned the value of 5.0 and the rarlable A 1 s eimply the average of $X, Y, Z$. Therefore, we print $(3+4+5) / 3=4$. 


\section{$2.7 \quad 6090$}

often it becones necessary to divert from the instruction stream. This is a technique called "branching" which is performed by the GOPO (or GO TO) statement. If we wish to not execute the next sequential instruction, we insert a GOPO atatement which tranfiers control to some other instruction. This instruction in question must have the correoponding statement number as the statement number in the GOIO statement; therefore, the GOrO statement appears as follows:

175 GOrO (statement no. of statement control is to be passed to)

If control is presently at instruction 200 and we wish to branch to the instruction with statenent number 500, we have

\section{GOTO 500}

You may branch to an instruction already executed or ahead to one further along in the instruction stream. 2.8 IF

The IF statement 1s another type of control statement and is used for testing various relationships, allowing branohing to occur providing certain conditions are satisfied. The format of the If statement 18 as follows:

IF (statement) THEN (statement number)

The statement portion of the statement may take on many forms where we have variables from the program and tymbols mentioned in Section 1.1 . 
The statement number refers to the statement to which control is passed if the expression is affirmative.

Bxamples:
a. I IF $A=2$ THEN 200
b. 1 IF $A<4$ THEW 205
c. 1 IF $0<=7$ THES 106
d. 1 IF $D>8$ THEN 110
e. 1 If $D>=1$ THEN 180
f. 1 IF $\mathrm{E} \ll>10$ THES 250

In example a), if the variable $A$ had been assigned the value 2, we have an affirmative result and control is passed to the instruction at statement number 200. If $A$ is anything -lse, control passes to the next executable statement. In example f), if $\mathrm{B}=10$ then control passes to the next executable statement whereas for all other velues of $\mathrm{E}$, the branch to statement 250 will take place.

\section{Question}

Write a BASIC statement to do the lollowing:

Branch to statement 700 if the sum of variables $X 1$ and $X 2$ is negative.

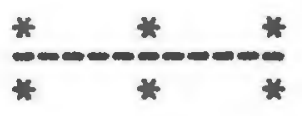

\section{Exlanation}

Eaing an If statement, we sum the rariables and tegt for negativity. 


\section{$2.9 \quad 30 R$}

To execute a series of instructions a number of times, a $100 p$ is formed to avold repetitious coding. The loop 18 Intiated by the FOR statement and terminated by the MEXT otatement. The format:

FOR $($ variable $)=\left(\begin{array}{c}\text { tarting } \\ \text { value }\end{array}\right)$ to $\left(\begin{array}{l}\text { Iinal } \\ \text { value }\end{array}\right)$ STEP (increment) The variable must be a valid BASIC rariable which has not been used or one that will not be needed for later calculations. This variable will be assigned the "starting value" as the statements are exeouted unt1l the IrEXT statement is oncountered. When this occurs, the loop is completed and the variable is incremented (or decremented) by the "inerement" (i.e., may be $<$ ). If this new value does not exceed the rinal ralue", then the entire loop is executed again with this new ralue for the rariable; otherwise, control passes outside the loop to the next executable statement after the NGXP statement. 


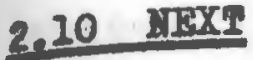

This statement acts to aignal the end of a loop. Only the variable used in the FOR statement appears in this statenent.

\section{Example:}

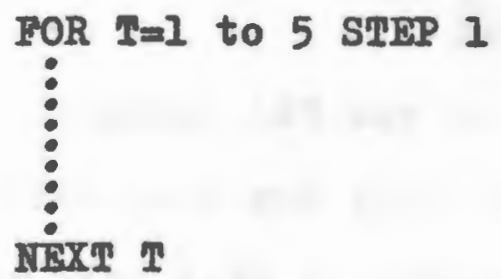

The statements from the FOR to the NFXT statement are axecuted five times. The flrst time $T$ will be assigned the value one and the fifth time, I 1s fire. If the "STEP" were two, then the loop would be executed three times with $T$ heving values 1,3 and 5. You noed not specify a STFP of 1 , 1.e.. "FOR Tal to 5" we assume STRP 1.

\section{Question}

1. Determine the purpose of the following coding:

163 POR SEl to 10

164 IET $\mathrm{B}=\mathrm{S}+\mathrm{E}$

165 NEXT S

2. Change statement 163 so as not to change the problem ( 2 ways).

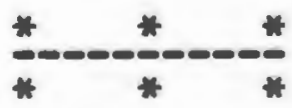




\section{Ixplanation}

1. The variable $\mathrm{S}$ is assigned values of 1 - 10 and each time the value is added to the sum of previous values. Thus we have the sum of the numbers from 1 to 10

$$
\sum_{S=1}^{10} S
$$

2. Statement 163 may be written by including the assumed STIF size and also by changing initial and final values with a negative step.

163 FOR $S=1$ to 10 STEP 1

or

163 FOR S=10 to 1 STEP -1

2.11 BND

The first phase that a program encounters is the complation phase where all the instructions are trenslated into machine (object) coding in order to have a machine program" for the second phase, execution. The END statement is used to algnal end of compilation in the initial phase. Once compilation ceases and there have been no errors found, the program is executed; otherwise, a list of errors is printed and execution does not take place. There may be only one IND statement in a BASIC program and it must be the last statement of the program. This statement is categorized as non-executable. 


\subsection{Input}

This statement acts as a conversational read statement which simply means that when executed, the console will pause and wait for the user to input data. For example, IIPUT I when executed will cause the program to stop and seek data which will be supplied by the user through the keyboard of the remote console.

To read six variables in this manner, we may have the following:

97 INPUT $\mathrm{N}, \mathrm{J}, \mathrm{K}, \mathrm{B}, \mathrm{E}, \mathrm{R}$

Each value typed in on the console must be separated from other values by a comma. The first value will be assigned to $\mathrm{N}$, the second to $\mathrm{U}$, etc. It is wise to print a literal message just before this statement indicating exactIf what input is desired.

\section{Questions}

1. Bxplain the differences between the READ and INPUT statements.

2. Write a short program to continually read in from the console two numbers and print out their sum only if it is positive.

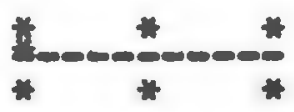




\section{Explenations}

1. The IMPUT statement allows one to assign values to varlables during exeoution whereas the READ atatement must have the values for the variables in the data block before execution. The IIIPU statement doesn't use the data block at any time.

2. 100 IXPUT 6, H

200 IIET $P=G+H$

300 If $P<=0$ THES 200

400 PRIIIT $F$

500 GOTO 100

600 HID 


\subsection{DFF}

One may define a function whlch can be used repeatedly In the program by using a function name consiating of FI and some other letter and the following:

(statement no.) DEF (function name) = (function)

We may define the function $x^{2}+2 I+1$ the following way:

$160 \operatorname{DEF} \operatorname{FIT}(X)=x \mid 2+2 * X+1$

Deing this function and the following coding, what world be the value of $B$ ?

161 IET $A=2$

162 IEST B-PHT(A)

The correct answer 189 since the value of $A$ (2) w1ll be used for $X$ in the FII function.

1.e., $2 \mid 2+2 * 2+1=4+4+1=9$

\section{Question}

Write a function for the following:

$$
\frac{y^{3}+25 y^{2}-(y+1)}{7\left(y^{2}+6\right)^{2}}
$$

\section{Explanation}

An acceptable result would be

$$
100 \operatorname{DEF} \operatorname{FIZ}(Y)=(I|3+25 * I| 2-(Y+1)) /(7 *(I \mid 2+6) \mid 2)
$$




\subsection{STOP}

The STOP statement signals the termination of execution. vnlike the FID statement, there may be more than one STOP otatement in the program. The STOP statement is categorized as a control statement and may appear anywhere in the program. Question
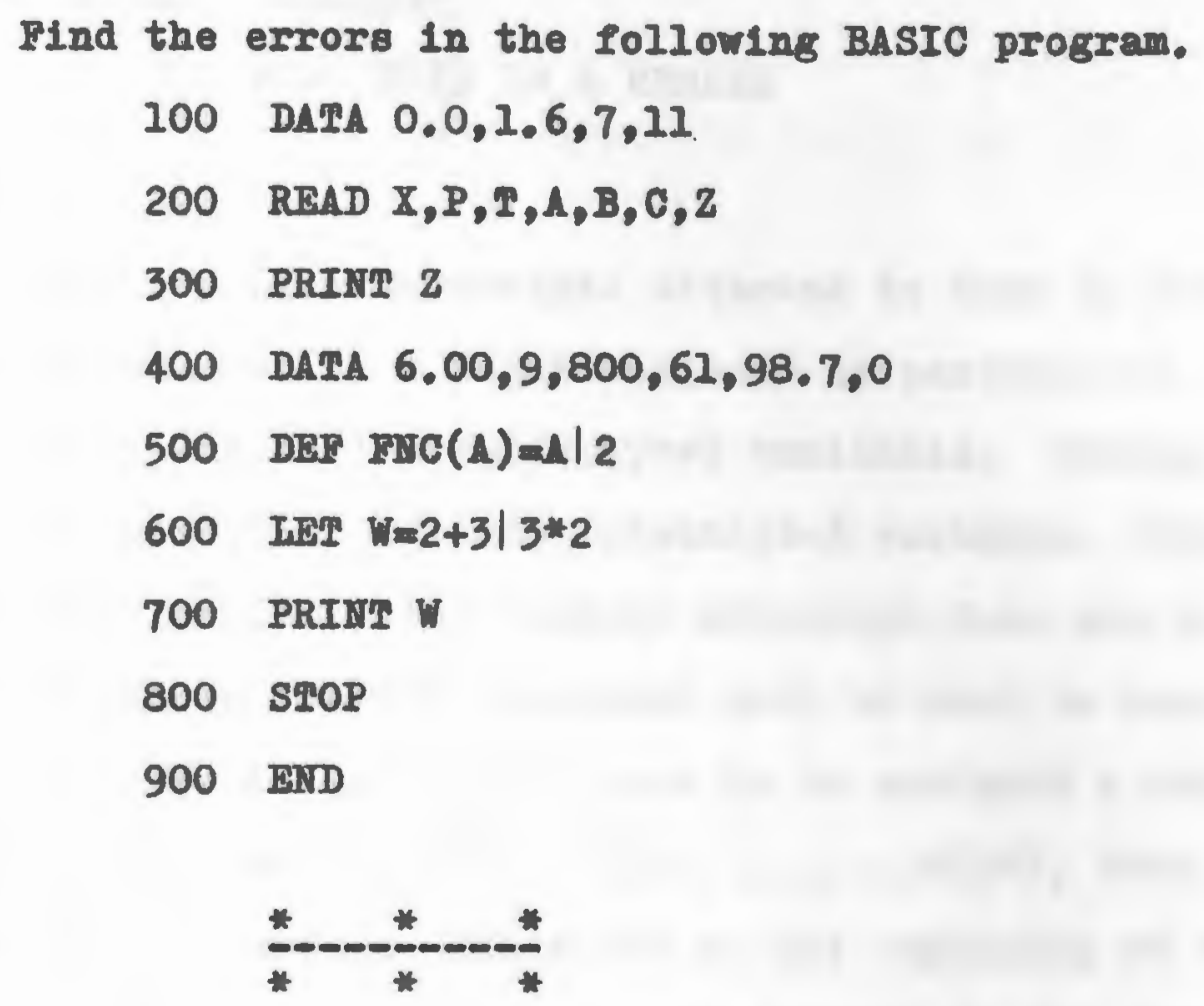

\section{Bxplanation}

There are no errors in this program. The data block consists of 10 values and since we wish to print out $z$, the serenth value, we have an answer of 800 . The variable is computed by considering the priorities mentioned in Chapter 1. Pirst we exponentlate, then multiply, and Pinally add. Thus the ralue for $W$ is 56. 


\section{$2.15 \mathrm{R}$ FHA}

To Insert comments into the program, we use the RBM tatement. Once the RPM is encountered, the remaining information on that line is treated as comment and is not compiled Into the program. This is used to ald you in better describing jour program. Bxamples

\section{RBM THIS IS A RBMARK}

\subsection{DIM}

Variables may have subsoripte attached to them by having the variable followed by a digit enclosed in parentheses. These variables are called subsoripted variables. Storage space must be reserved for each subscripted rariable. This is done autoantically if the largest subscript does not exceed 10. Otherwise the DIM statement must be used to reserve this storage. If the varlable $s$ were to be assigned a maximum of 20 values, namely, $s(1), s(2) \ldots . . . . . . s(20)$, then we would need the following: DIM S(20) at the beginning of the program. If the variable $V$ were to be treated in the same manner, we would have

$$
\text { DIM } s(20), \nabla(20)
$$

Therefore, if a variable is to be treated as a oubcorlpted variable and we do not wloh to asaign more than 10 distinct values, we may omit the DIM statement. 


\subsection{GOSUB}

In programing languages, a term which commonly arises is "subprogram", of which there are varlous types. We will pention only the subroutine which is a blook of coding to perform a particular funotion. This subprogram is branched to by means of "GOSUB" and the statement number of the first instruction of the subroutine. When completed, control retums to the statement 1mediately following the GOSUB statement.

\subsection{RETURN}

The last statement of every subroutine is the RETURN statement which simply transfers control back to the statement Immediately following the GOSOB statement. 


\subsection{Built-In Functions}

Mentioned in Section 2.13 is a method of creating funct10ns. There are functions whlch are already avallable to BASIC programers. These functions are called built-in functions. They are:

\begin{tabular}{|c|c|}
\hline $\sin (x)$ & sine of $X$ \\
\hline $\cos (x)$ & where $X$ is expressed \\
\hline $\operatorname{TAN}(\mathrm{X})$ & in radian measure \\
\hline $\operatorname{ArAN}(\mathrm{X})$ & arctangent of $X$ J \\
\hline $\operatorname{ABS}(X)$ & absolute value of $x$ \\
\hline $\operatorname{INT}(x)$ & largest integer not greater than $X$ \\
\hline $\operatorname{IOG}(X)$ & natural log of $\mathrm{X}$ \\
\hline $\operatorname{ExP}(x)$ & $e^{x}$ \\
\hline $\operatorname{SQR}(X)$ & square root of $X$ \\
\hline $\operatorname{sen}(x)$ & $\begin{array}{l}\text { yields }-1,0 \text {, or }+1 \text { for } X \text { negative, zero, } \\
\text { or positive; respeotively }\end{array}$ \\
\hline
\end{tabular}

RID generates random number between 0 and 1

To deternine the square root of $X$ and assign the result to $I_{\text {, we have }}$

\section{$100 \operatorname{INET} \mathrm{Y}=\mathrm{SQR}(\mathrm{X})$}

To evaluate $e^{x+y}$, and assign the result to $\Lambda$, we have $100 \operatorname{IDT} \Lambda \operatorname{mixP}(X+Y)$

All the other functions work this way. 


\subsection{Humeric Applications}

In this section we shall 1llustrate how useful the builtin functions are by programing oome simple examples.

a. Find the square root of the numbers from 1 to 20

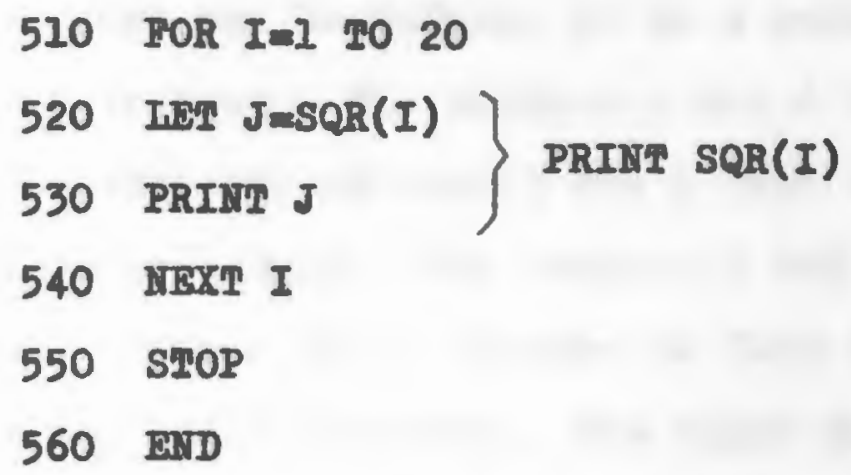

b. Find the SIII, COS, and TAII of 20, 25, 30, 35, 40 and 45 degrees.

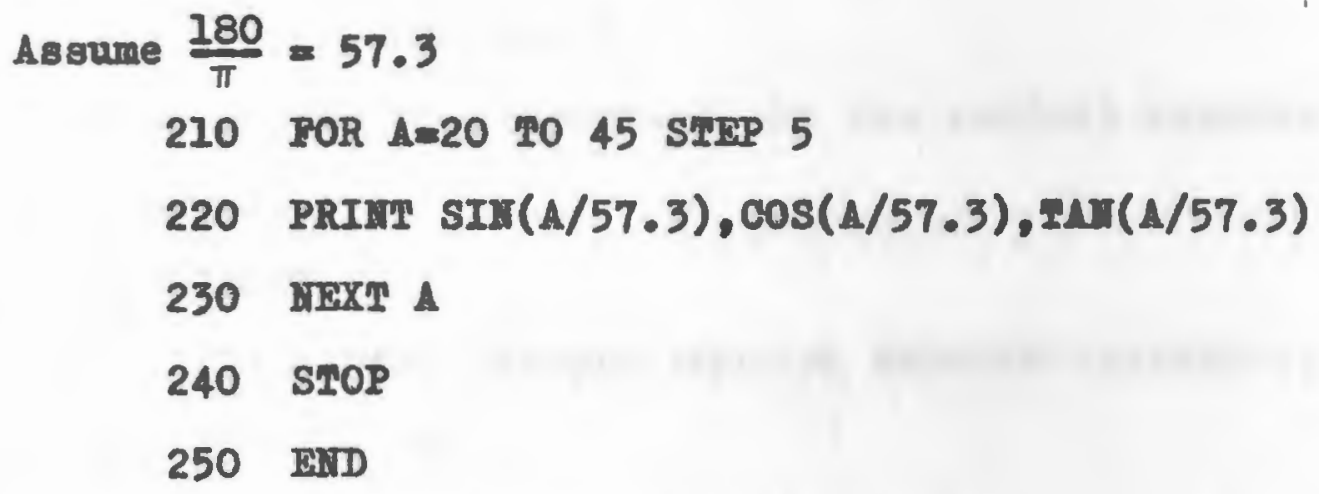

c. Show that the random number generator generates a positive value.

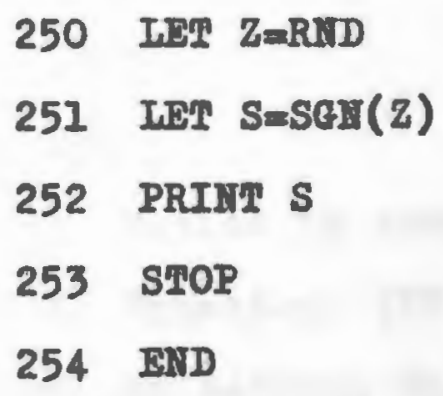


1. Problens and Solutiong

\section{Problem 1}

SQUARE ROOT PROBLEM

A perfect square may be defined to be a number whose square root $1 \mathrm{~s}$ an integer. The numbers 1 and 4 heve square roots 1 and 2 respectively whereas 2 and 3 hare square roots 1.414 and 1.732 respectively. The numbers 1 and 4 are thus jorfoct squares. Write a BASIC progran to find all the perlect squares in anj given interval. The input ahould be via the renote oonsole and should accept the beginning and ending value of the interval.

\section{Solution 1}

The following program determines all the perfect squares in a given interval.

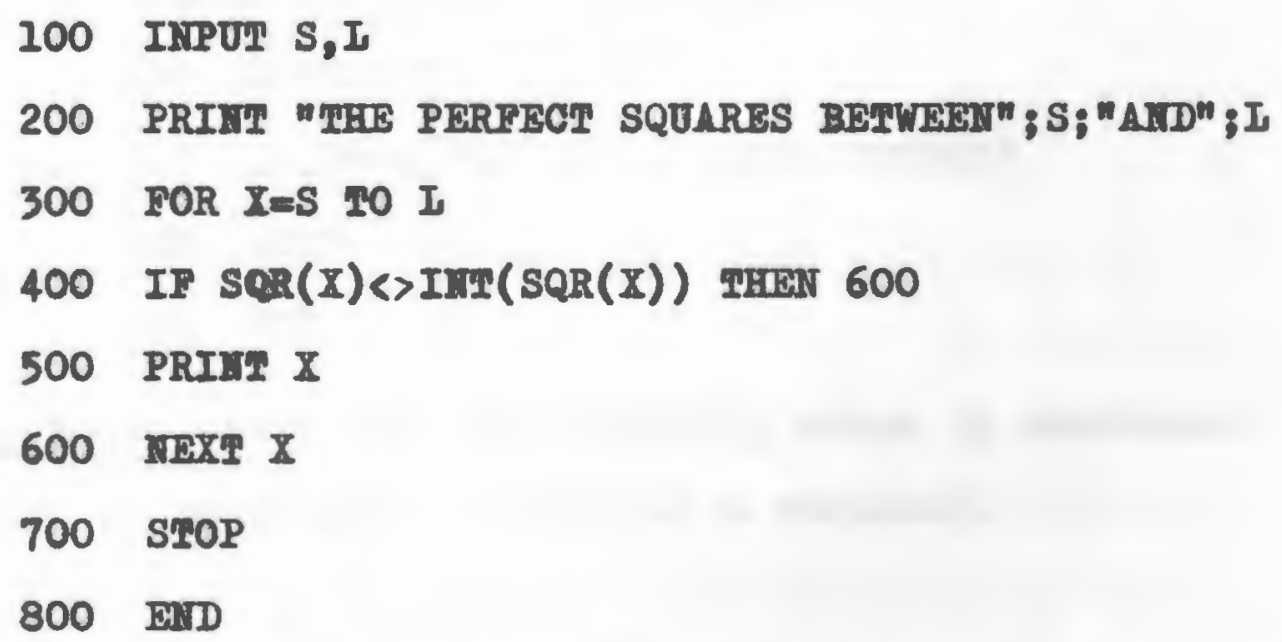

Prepreming Hote: Notice in statement 400 the nesting of the bu1lt-1n functions INT and SQR. A I00p to consider all numbers between the end points is constructed from statement 300 to statement 600 . 


\section{Problem 2}

\section{PRIME NUMBER PROBIFM}

A prime number is one which is divisible only by 1 and 1tself. Examples of prime numbers are 2, 3, 5, 7, 11, 13,... Write a BASIC program to read via terminal a number and then determine whether or not it is a prime number. Print out the number and some remark as to whother or not it is prime.

\section{Solution 2}

The following program determines whether a given number 18 prime or not.

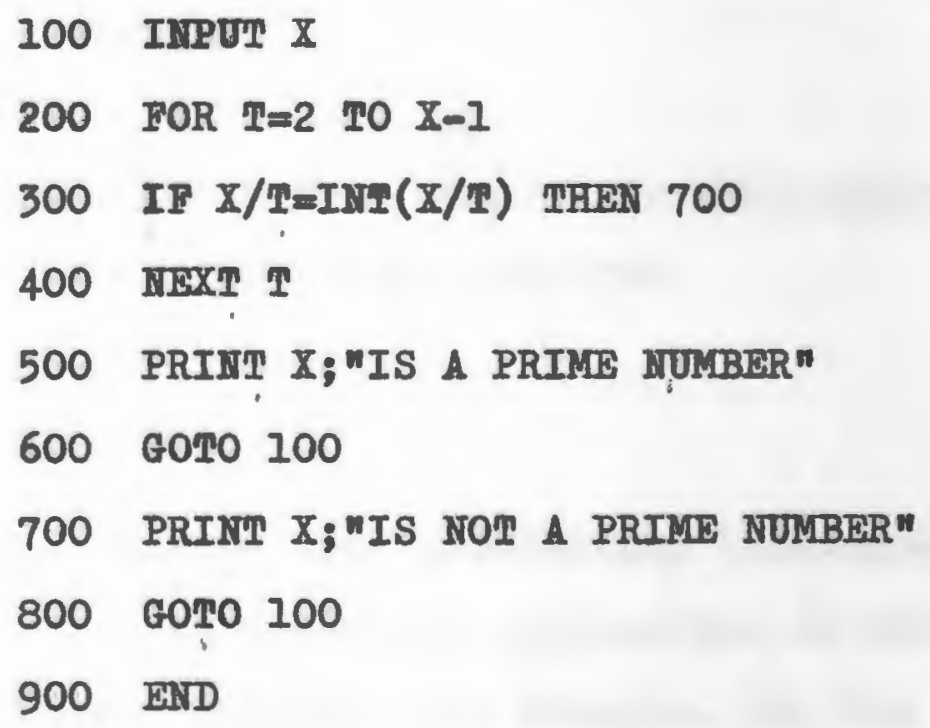

Programining Note: Note that the limiting value in statement 200 is an expression and not a variable. 


\section{Problem 3}

AREA-PERIMETER PROBLEM

For a rectangle of length $\ell$ and width $w$, area is defined to be $l \times w$ and perimeter $2 l+2 w$. Write a program in BASIC that will accopt from the terminal a value for the length and a value for the width. Print out the length, width, area, and perimeter of the rectangle with appropriate labels. Write so as to handle an infinite number of rectangles.

\section{Solution 3}

The following is a solution to finding the area and porimeter of a rectangle:

$$
\begin{aligned}
& 100 \text { INPUT I,W } \\
& 200 \text { PRIMT "ILEH WIDPH AREA PERIMETER" } \\
& 300 \text { PRINT I;W;I*W;2*I+2*W } \\
& 400 \text { GOTO } 100 \\
& 500 \text { END }
\end{aligned}
$$

Programming Note: Unlike some programing languages, BASIC allows you to print out expressions as well as variables. FORPRAN, for example, has the expressIon aseigned to a variable name which in turn is printed out. Iote that the first PRIII statement acts as a heading for the four computed values. 


\section{Problen 4}

\section{EUCHID'S ALGORITHM}

Fuclid's algorithm is a technique used to determine the peatest common divisor of two integer numbers. The procedure 1s quite simple. First divide the larger by the smaller to obtain a quotient and remainder. If the remainder is not oqual to zero, replace the larger by the smaller and the amaller by the remainder (in that order) and repeat the divi10n. When the remainder is zero, the greatest common divisor (ged) is the smaller at that time, not necessarily the smaller number at the beginning of the problem. The following flowchart will ald you in solving the problem. It is assumed the numbers are in descending order; otherwise a test would be necessary and this is quite trivial. Test your program with numbers 21 and 20.

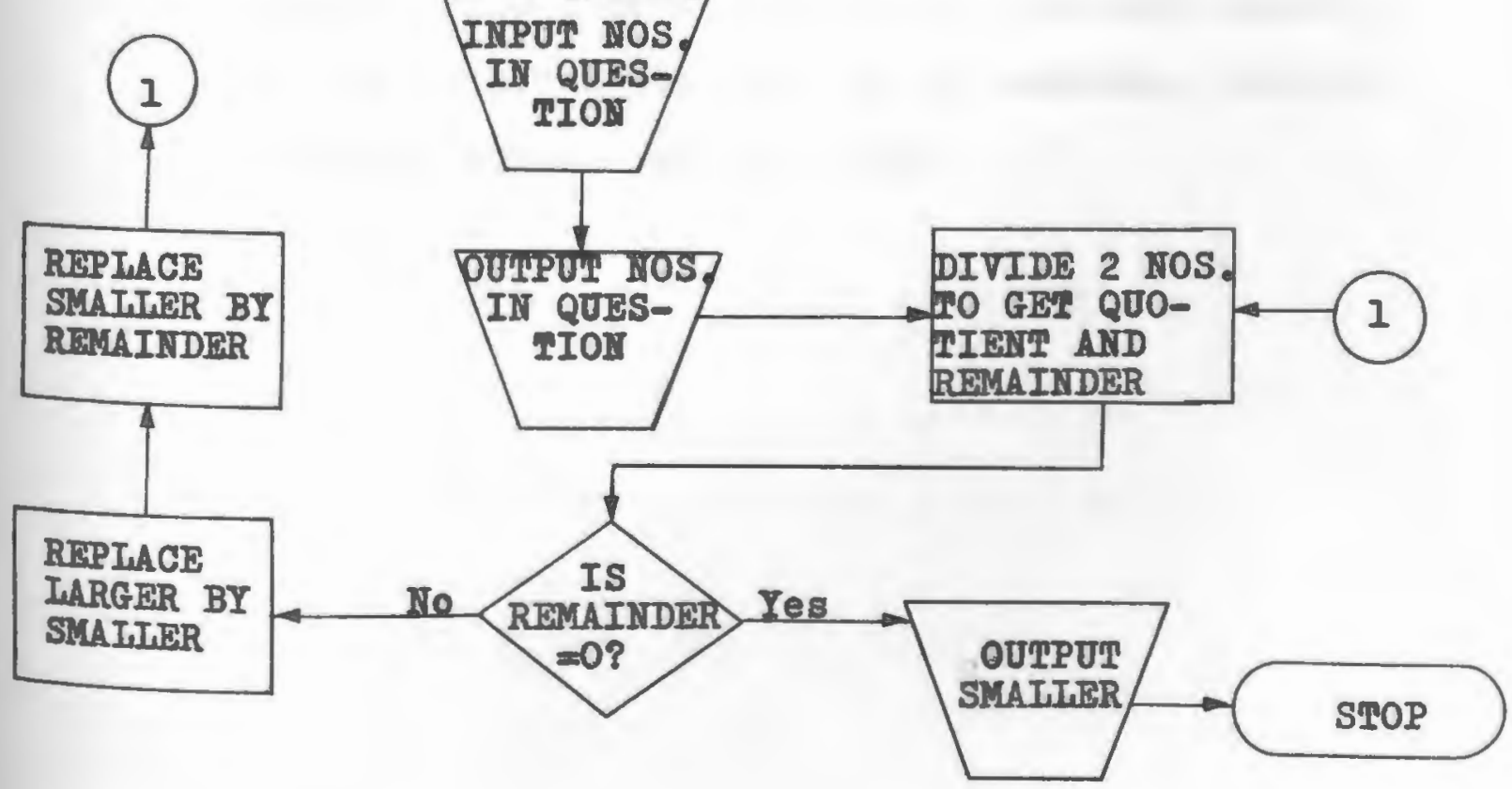


Solution 4

The following is a solution to find the greatest common divisor of two numbers using Buclid's algorithm. Involved is a loop to handle more than one set of numbers.

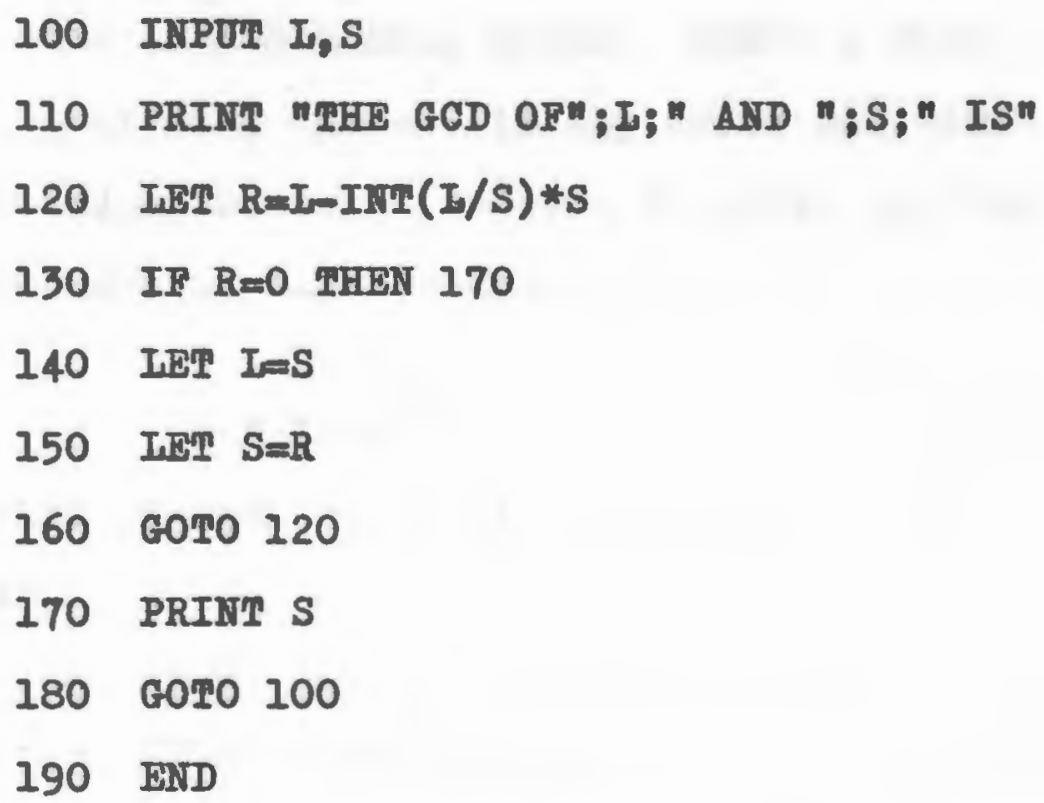

Programming Note: Notice that this program doesn't contain a SPOP statement. Inrolved is a branch to statement 100 for a new set of numbers after one set is computed. To stop this program, you must cancel 1t. To consider just one set of numbers, replace statement number 180 by a STOP. 


\section{Problem 5}

SORT PROBIKHY

Some problems demand the use of a routine to sort numbers. For example, a teacher may wish to have the scores from an exam listed in descending order. Write a BASIC program that will input five numbers in any order and print them out in descending order. (Be sure to print out the array before the sorting takes place.)

\section{Solution 5}

The following program will sort five numbers into descending order.

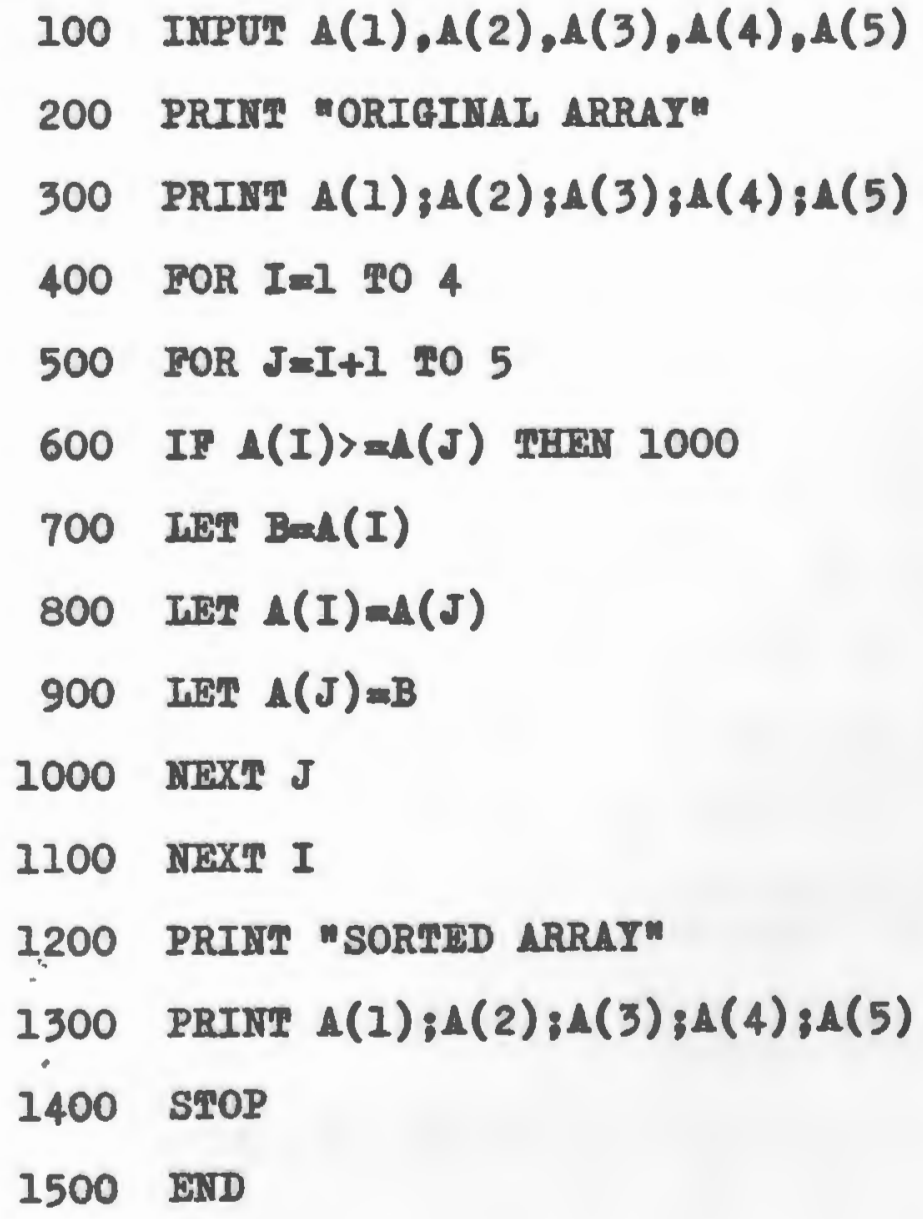


Brograming Jote: The array 1s not dimensioned since we are assigning lesg than ten values to 1t. The two loops, one within the other is called "nested" 100ps. The Inner most loop is executed to completion while the outer loop stays fixed. Then the outer loop 18 increased and the inner one repeated. Completion is reached when the outer loop has reached its limit and the Inner has been executed for this value of the outer limit. 


\section{Appendix A}

Matrix Operations

Statements

MAT READ A

MAT PRINT A

MAT $\triangle=B+C$

wat $A=B-C$

MAT $A=B * C$

MAI $A=(B) * C$

$\operatorname{MAT} \Lambda=\operatorname{InT}(B)$

MAT $\Lambda=T R H(B)$

MAT AmCON

HAT A=ZER

MAT $\Lambda=I D M$
Purpose

read a matrix

print a matrix

matrix addition

matrix subtraction

matrix

multiplication

wultiply matrix by scalar

inverse of matrix

transpose of matrix

matrix of unity

zero matrix

1dentity matrix
Fxplanation

Reads from data statement values and stores them in matrix $\wedge$ rowwise.

Print out all values that are assigned to matrix 1.

Add corresponding elements of matrix $C$ and matrix $B$, gtoring results in matrix $A$.

Subtract correspondIng elements of matrix C from matrix B, otoring results in matrix A.

Nultiply correspondling lements of matrix $C$ by matrix $B$, storing reaults in matrix 4 .

Multiply aatrix $C$ by the number (or expression) $B$ and store results in matrix $\Lambda$.

Take the inverse of matrix $B$ and store in matrix $\Lambda$.

Store the transpose of matrix $B$ in matrix $\Lambda$.

Set all elements of matrix \& to "l".

Set all elements of matrix \& to "On.

Set matrix 1 to identity matrix (1.e., main diagonal elements are "I"; off-diagonal elementa ere non) 


\section{Appendix B}

Suggested Problems

1. Write a BASIC program to print out a table of sines, cosines, and tangents for angles of $0^{\circ}$ to $90^{\circ}$.

2. Write a program to find the factorial of an integer $N$.

3. Write a program to compute the interest for rates from 1\% to 25\% using a constant principal and time.

\section{IHTERESTMPRITCIPAI X RATE X TIME}

4. Write a program to compute the mean and standard deviation of $N$ numbers.

$$
\sigma=\sqrt{\frac{\Sigma z^{2}}{u^{2}-\bar{x}^{2}}}
$$

5. Write a program to print a table for converting $1-12$ inches to centimeters ( 1 inch $=2.54$ centimeters).

6. Write a program to evaluate SUM where

$$
\begin{aligned}
\operatorname{SUM}=\sum_{J=1}^{N} 3 \pi(2)^{J} \cos \left(42^{\circ}\right) \text { where } \pi & =3.14159 \\
N & =12
\end{aligned}
$$

7. Write a program to find the square root of any number, except zero.

If the number is negative, print out its square root as an imaginary number, e.g. $\sqrt{-4}=2 I$.

8. Write a program to determine the following ratio for values of $X$ from 100 to 1000 in increments of 100

$$
\frac{\Delta \cdot \operatorname{IOG}(X)}{\mathrm{X}}
$$

where $A$ is the number of prime numbers less than $X$. 
APPHIDIX C

PROGRAMTED BXAKIMATION IISPING WITH

QUESYIOIS ATD SARPIE EXAIS 
/display baslcx

m. 0073 action in progress.

1.0001 ffe

1.0002

1.0003

). 0004

1.0005

1.0005

1.0007

1.0008

1.0009

1.0010

1.0011

1.0012

1.0013

1.,0014

1.0015

1.0015

1. 0017

1.0018

1.0019

1.0020

1. 0021

1. 0022

1.0023

1. 0024

1.0025

1. 0026

1. 0027

1. 0028

1.0029

1.0030

1.0031

1.0032

1. 0033

1.0034

1.0035

1.0036

1. 0037

1.0038

1.0039

1. 0040

1.0041

1. 0042

1.0043

1.0044

1.0045

1. 0046

1.0047

1.0048

1. 0049

1.0050

dimension kev(10), msl $(50,20), i$ an: $(50)$, ques $(50,20)$, answer $(50,20)$

integer bank, pick $(10)$, select $(50)$, acct $(50,4)$

instructions and description

write $(6,1000)$

initial values for counters

$k 1=0$

$k 2=0$

$k 3=0$

$k+=0$

innut questions, solution choices, description of correct answers

read $(5,1800)$ hank, noask

$\operatorname{read}(5,1.900)($ ans $(i), 1=1$, bank )

तo $1 \mid=1$, bank

$\operatorname{read}(5,1200)($ ques $(i, j), j=1,20)$

read $(5,1200)$ (answer $(i, j), j=1,20)$

$1 \operatorname{read}(5,1200)(\mathrm{ms} 1(i, j), j=1,20)$

तn 7 i 1 , bank

$7 \operatorname{read}(5,1600)(\operatorname{acct}(1, j), j=1,4)$

c

generate a key for thls exam as well as ten random questlons

call time (iu)

$i u=i u * 2+1$

$v=2.0 * 32$

$I x=5 * 15$

do $500 \quad i=1$, noask

I $11 \equiv \mid \mathrm{u} \| \boldsymbol{x}$

$5 n, 0 \operatorname{key}(i)=i f i x((i u / v+0.5)+4)+1$

तo $6001=1$, noask

$602 i u=i u * i x$

Imos $=1 \mathrm{fix}((\mathrm{iu} / \mathrm{v}+0.5)$ thank $)+1$

If (select (Iposs) $602,601,602$

601 select $($ I poss $)=1$

$c$

600 piek(i) =ipnss

c prepare each question Into format specified by key

ask questions and determine if qusestion is to be asked agaln

तn $100 \mathrm{nq}=1$, noask

ipapick (nq)

if $(\mathrm{ms})(1 \mathrm{p}, 13)+707340859) 2,3,2$

3 If $($ Ians $(i p)-4) 4,5,4$

$\operatorname{key}(n q)=4$ 
1.0055

1.0057

1. 0058

1.0059

1.0060

1.0061

1.0062

1.0063

1.0064

1.0065

1.0066

1.0067

1.0068

1. 0055

1.0070

1.0071

1. 0072

1. 0073

1.0074

1.0075

1. .0076

1. . 0077

1. 0078

1. 0079

1. 0080

1. 0081

1. 0 C) 82

1.0083

1. 0084

1. 0085

1. 0086

1. 0087

1. 0088

1.0089

1.0090

1. 00991

1.0032

1.0093

1. 0094

1.0095

j. 0096

1. 0097

1.0098

1.0099

1.0100

1.0101

1.0102

4 if $\ln 11$

$6 \operatorname{key}(n \pi)=$ ians $(i p)$

ge to 11

2 तo 10 in $\mid=1,4$

$k=i$ ans $(i n) * 4-(i \mid-1)$

$1=\operatorname{key}(n q) * 4-(i i-1)$

$m=m s i(i p, k)$

$m s i(i n, k)=m s \mid(i n, 1)$

in $\mathrm{msl}(\mathrm{ip}, 1)=\mathrm{m}$

11 write $(6,1,500) n a$, (aises $(1 p, i), 1=1,20)$

12 write $(5,1008)(\mathrm{ms} i(i p, j), j=1,16)$

call subby (key, nq, k1,k2,k3,k4, ily,answer, i $p, a c c t)$

$c$

c 311 nuestions have been asked

c output results

write $(6,170 n)$

1700 format $(/ / / /$ 'you have just completed the first exam in basic', $/ /)$ write $(6,1701)$

1701 format $(i, 5 x$.'summary', $/)$

write $(6,1702) \mathrm{kl}, \mathrm{k} 2, \mathrm{k} 3$

17 2 2 format ('correct cholce first try' $13 . /$ 'correct choice second try'

$1,13,1$, 'answer was supplied', 13,11 )

write $(6,1703)$

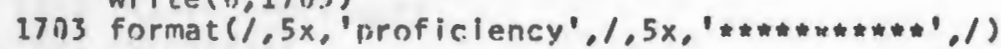

c compute sturent proficiency

$p=(k 1+k 2 / 2) *(100 . /$ noask $)$

if $(p-89) 60,331,331$

60 if $(p-79) 70,333,333$

.

c

70 if $(p-69) 8 n, 335,335$

80 write $(6,1704)$

17 ก format $(10 x$, poor') go to 20

335 write $(6,1705)$

1705 format ( $10 x$ ' $f a i r$ ') en to 20

333 write $(6,17 n 6)$

1706 format (10x, "good") go to 20

331 write $(6,1707)$

1707 format ( $10 x$, 'excellent')

20 write $(6,1708)$

1708 format $(/ / 1 / 1)$

write $(10,16 n 0)((\operatorname{acct}(1, j), j=1,4), i=1$, tank $)$ stop 
1. 0117

1.0118

1.0119

1.0120

1.0121

1.0122

1.0123

1.0124

1.0125

1. 0126

1.0127

1.0128

1. 0129

1.0130

1. 0131

1.0132

1.0133

1.0134

1.0135

1.0136

1. 0137

1. 0138

1.0139

1.0140

1.0141

1. 014 ?

1.0143

1.0144

1.0145

1. 0146

1.0147

1. 0148

1.0149

1.0150

1. 0151

1.0152

1.0153

1.0154

inno format ' 1 ', 'this prozram is designed to test your knowledge of bas $1 \mathrm{c}^{\prime}, \mathrm{l}$, 'once you have completed the exam, a summary will appear', 2 'showing how many nuestions were answered correctiy on the first 3./.'attempt and how many on the second at tempt. If the ', 'correct 4 cholce has not been marle at this point, a full des-' $/$ 'cription

5 is giver: for the correct answer. answer each', 'question as quick 61 y as posslhie', //)

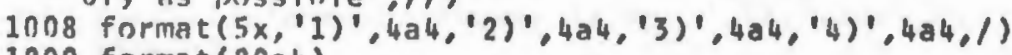

1200 fnrmat $(20 a 4)$

$15 n$ format $(/ /, 1 x, 12,1 \times, 20 a 4)$

16 no format $(4 i 5)$

1 ano format $(212)$

1900 format $(4012)$

$$
\text { end }
$$

If tc

subrout ine subby(key,nn,k1,k2,k3,k4, I1y,answer, Ip,acct)

dimension key (10), answer $(50,20)$

integer acct $(50,4)$

99 write $(5,100)$

100 format ('answer')

c input and correct sturient answer

$\mathrm{k} 4=\mathrm{k} 4+1$

1000 read $(9,200)$ inputt

200 format (11)

go to $(205,2.05,205,205)$, inputt

write $(6,105)$

105 format $(\mathcal{H}$, 'invalid response', $/$, 'you must indicate your answer by th le number 1,2, 3, or 4.1,1) go to 99

205 if $(k 4-1) 298,298,301$

2.98 irec=inputt En to 303

301 if (irec-inputt) $3 n 3,302,303$

322 write $(6,600)$

600 format ( $/$ 'this answer has already been given. try again. ', /) on to 1000

303 if (inputt-key(nn)) 1, 920,1

1 write $(6,300)$

300 format (/, 'wrong answer', /) If $(k 4-2) 2,935,2$

$2 k 4=k 4+1$

write $(6,400)$

400 format $(/$. 'try this one again', /) go to 1000

920 if $(k 4-1) 3,93 n, 3$

$3 k 2=k 2+1$

$\operatorname{acct}(i p, 3)=\operatorname{acct}(i p, 3)+1$ 


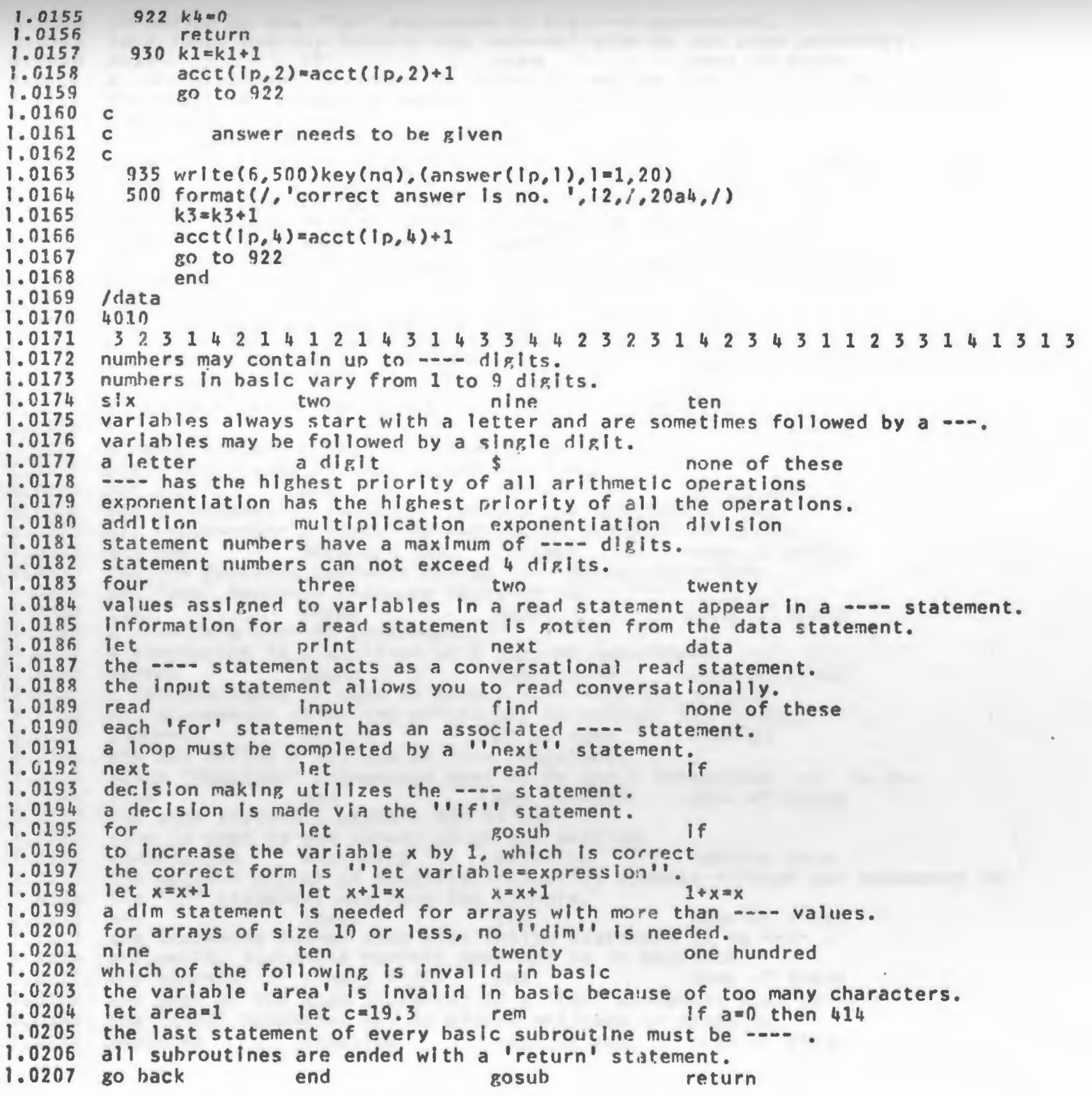


an option on the 'for' statement is the -.... parameter. in a loop. one may specify the interval size by the step parameter.

1. 211 a - - statement is needed in order to use the 'data' list more than once.

the 'restore' statement returns the user to the beginning of the data block. reread data

1.0214 a --- causes short spacing to the next element.

1.0215 a comma is for long spacing and a semi-colon for short spacing. perion semi-colon apostrophes nuotes parenthesis expresslons withins the valtie of the Innemost express abbreviated simple nested basle

1.0226

1.0227

1.0228

1.0229

varlables may be separated hy arithmetic operators. parenthesis dashes blanks none of these

Dubscrint of an array may be a variahle or a -..-

subscripts may be varlables, constants, or expressions.

a basic statement mist be container on baslc statements may not exceed one line.
one page one line
three lines
15 columns

the trigonometric functions require one argument in ....

all trigonometric functions require an argument in radians. degrees degs and rads radians

the sgn function produces orie of ...- different values.

the 'sgn' function produces $+1,0$, or -1 .

two

$\begin{array}{ll}\text { matrix } & \text { gnsub subroutirie } \\ \text { a rem statement is used to insert } & \end{array}$

none of these

a rem statement is used to insert rem statements allow the prozrammer to comment his program. comments errors print outs

one may define a maximum of -..- functions.

since 'function' statements must be fn and a letter,max. no. Is 26. five two
the stop statement signals end of hundred none of these

compllation to end execution of the program.

printing reading data

the Iff

statement may have two symhols.

presently, statement numbers neel not be in sequence.

one hundred ninety eight one
the slgn of the step increment of a 'for' statement must he

one hundred ninety eight one
the sign of the step increment of a 'for' statement must he

the slgn of the step increment of a 'for' statement must
the 'steo' narameter may he elther mositive or negative.

positive negative pos. or neg.

none of these 
the variahle for the 'next' 5 tatement corresponds to the variable in the -.-.

for statementar

there are a total of -..- arithmetic symbols in basic.

1.0264

1. 0265

1. 0266

five

four

six

three

1.0267

to test inequallty, we must use -.- symbol(s).

use the 'less than' and 'preater than' symbols.

1.0268

1.0269

1. 0270

wo

three

none of these

1.0271

1.0272

In seneral, division always has nrlority over $-\infty$.

unlass otherwise speclfled, division has prlority over addition and subtractlon.

exponentiation multiplication subtraction none of these

a valid hasic variahle has a maximum of -... characters.

1.0273

varlables may have elther one or two characters hut never any more.

four three two

one

the end statement is classified as a -..- statement.

1.0275 'end' is used to halt compllation and is termed 'non-executable'.

1.0276 non-executable executable termination none of these

1.0277 a 'print' statement may print out only

1.0278 ore may print out blank lines by inserting tianks in the quotation marks.

1.0279

variabies

vars, and lits. none of these

1.0280 a let statement .... contains an arithmetic symhol.

1.0281 arithmetic operations may or may not take place in 'let' statements.

1.0282

ocassionally always never none of these

1.0283 the statement 10 let $p=p+1$ performs what is known as - -

1.0284 to increase the value is to increment.

1.0285

1.0286

1.0287

updating changing

incrementing

addition

the 'goto' statement is used for what is terined -...-

1.028

goto statements are used for unconditional branching.

going ahear

loopling

1.0289 which of the following is invalid

1.0290 'mat $x=m a t y+c$ ' is not in any of the forms for inatrix operations.

1.0291 mat a wh-c

mat $a=(b) * c$

mat $x=$ mat $y$ *c

mat orint $x$

m.0072 begin activity. 
m.0072 begin activity.

/purge keep(150?)

m.0073 action In progress.

purge activity complete

m.0072 begin activity.

Irun

m.0073 action in progress.

end of compllation main

end of compilation subby

this program is deslgned to test your knowledge of baslc

once you have completed the exam, a summary will appear

showing how many questions were answered correctly on the first

attempt and how many on the second attempt. If the

correct choice has not been made at this point, a iull des-

cription is given for the correct answer. answer each

question as quickly as possible

1 to increase the variable $x$ by 1 , which is correct
1) $x=x+1$
2) let $x+1=x$
3) let $x=x+1$
4) $1+x=x$

answer

3

2 the subscript of an array may be a varlable or a ..... 1). 2)/

answer

wrong answer

try this one again

1

this answer has already been given. try again.

2

wrong answer

correct answer is no, 4

subscrlpts may be varlables, constants, or expressloris. 
3 a valld bastc varlable has a maximum of --. characters.
$\begin{array}{lll}\text { 1) four } & \text { 2) two } & \text { 3) three }\end{array}$
2) two
4) one

answer

4

wrong answer

try this one again

2

4 to test inequality, we must use -..- symhol(s).
1) two
2 )one
3) three
4) none of these

answer

1

5 the varlable for the 'next' statement corresponds to the varlable in the -.-. 1) input statement 2 )read statement. 3) for statement 4 ) data statement

answer

3

5 the stop stotement signals end of .....
1) compllation
2 ) execution
3) printing
4) reading data

answer

2

7 numbers may contain up to -.-- digits. 2) inime 3) two

4) ten

answer

2

8 there are a total of $-\ldots$ arithmetic symbols in hasic.
1) three
2) four
3) six
4) five

answer

4 
9 a --- statement is needed in order to use the 'Hata' 1 ist more than once. $\begin{array}{llll}\text { 1) input } & \text { 2)reread } & \text { 3) data } & \end{array}$

answer

$\underline{4}$

10 a let statement -..- contains an arithmetic symbisl.
1) ocassionaliy
2 ) a Iways
3) never
4) none of these

answer

1

you have just completed the first exam in basic

summary

correct choice first try 8

correct choice second try 1

answer was supplled 1

proflelency

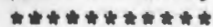

good

stop 00000
m. 0072 begin actin

m, 0072 begin activity.

/save keep(1602), sv

m.0073 action in progress.

flle saved under specified name(lock)

m. 0072 begin activity. 
linsert keep

m. 0073 action in progres 5.

m.0070 action complete.

lend

$\mathrm{mi} 0072$ begin activity.

frurge keen(1602)

m. 0073 action in prozress.

purge act|vity complete

m. 0072 begin activity.

Irun

m. 0073 action in progress.

end of compllation main

end of compliation subby

thls program is designed to test your knowledge of basic

once you have completer the exam, a summary will appear

showing how many questions were answered correctly on the first

attempt and how many on the second attempt. If the

correct cholce has not been made at this point, a full des-

crlption is given for the correct answer. answer each

question as quickly as possible

1 the subscript of an array may he a variable or a
1)+
2)/
3)*
4) none of these

answer

4

2 the stop statement signals end of -..-
1) compllation
2) printing
3) execution
4) reating data

answer

3 one may define a maximum of .... functions.
1) five
2) two
3) one hundred
4) none of these

answer

4

4 to increase the varlable $x$ by 1, which is correct
1) $1+x=x$
2) let $x+1=x$
3) $x=x+1$
4) let $x=x+1$

answer 
5 the statement number that must follow statement 99 is 2) ninety elght

answer

4

6 the sign of the step Increment of a 'for' statement must be -.--
1) nositive
2) negat I ve
3) pos. or neg.
4) none of these

answer

3

7 decislon making utilizes the --- statement.
1) for
2) let
3) If
4) gosub

answer

3

8 -.-- are used to separate varlables within the formula.
1) parenthesis
2) rasties
3) blanks
4) none of these

answer

4

9 a basic statement must be contalned on ----
1)one page
2) 15 columns
3) three lines
4) one IIne

answer

4

10 the 'goto' statement is used for what is termed -... .
1) moving along
2) branching
3) golng ahead
4) $100 p$ ing

answer 
you have just completed the first exam in baslc

summary

correct cholce first try 10

correct cholce second try 0

answar was supplied 0

proflclency

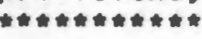

excel lent

stop 0nnO0

m. 0072 begin activity.

/save keep(1602), sv

$\mathrm{m} .0073$ action in progress.

flie saved under speclfied name(lock)

m. 0072 begin activity. 
APPEHDIX D

GENERATING PROGRAM FOR UNSOLVED PROBLEMS

WITH ORIGINAI PROBIEMS AND

SAMPIE EXERCISES 


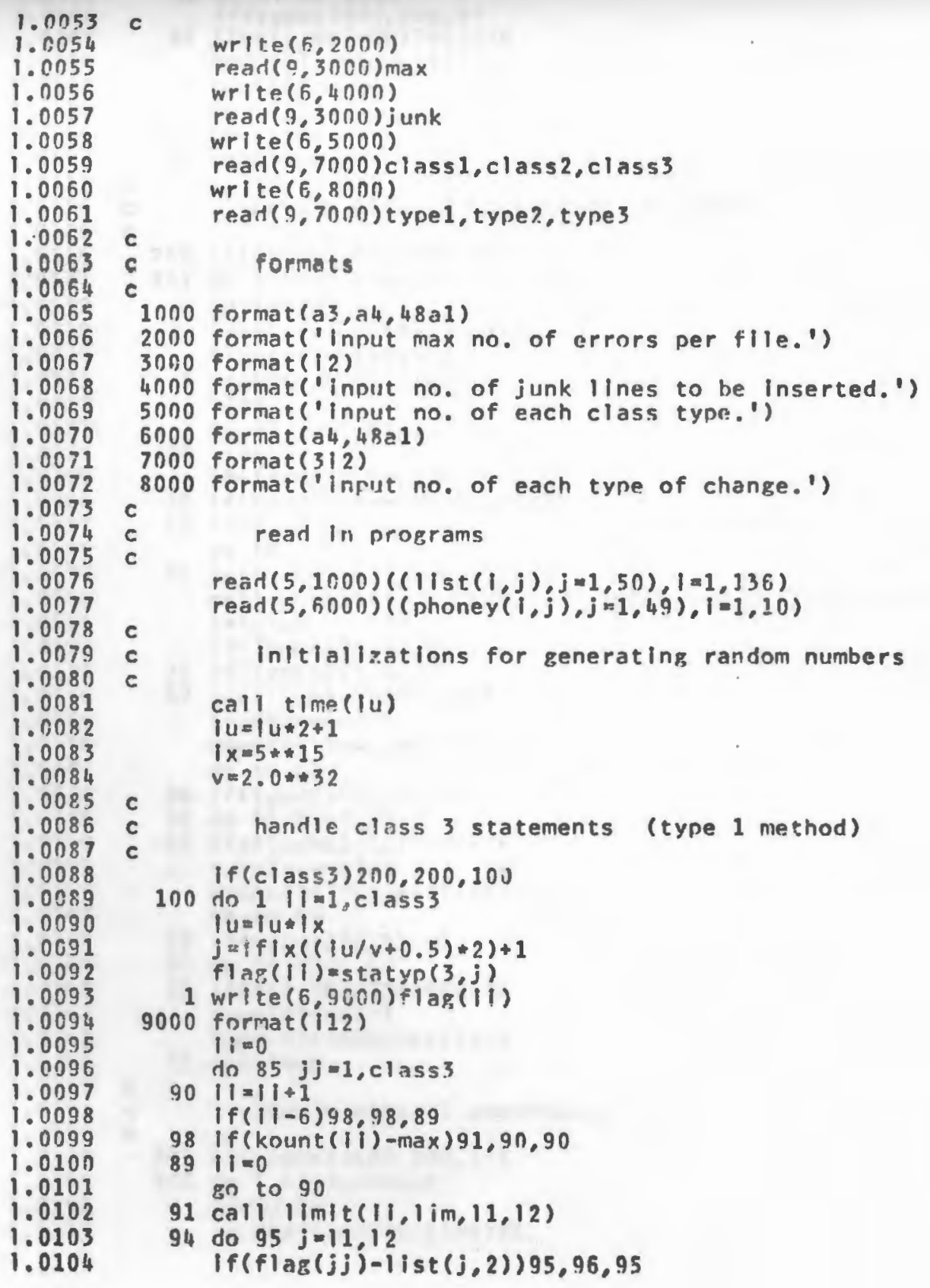


1.0105

1.0106

1.0107

1.0108

1.0109

1.0110

1. 0111

1.0112

1.0113

1. 0114

1. 0115

1. 0116

1. 0117

1.0118

1.0119

1.0120

1.0121

1.0122

1.0123

1.0124

1.0125

1.0126

1.0127

1.0128

1.0129

1.0130

1.0131

1.0132

1.0133

1. 0134

1.0135

1. 0136

1.0137

1.0138

1. 0139

1.0140

1.0141

1.0142

1.0143

1.0144

1.0145

1.0146

1.0147

1. 0148

1.0149

1. 0150

1.0151

1.0152

1.0153

1.0151

1.0155

1. 0156

6 do $97 k k=1,50$

If (typeI) $200,200,97$

$97 \mathrm{list}(\mathrm{j}, \mathrm{kk})=1077952576$

kount $(||)=$ kount $(||)+1$

type 1 = type $1-1$

go to 85

95 continue

85 continue

handle class 2 statements (priority to type 3 type 2 type 1)

200 if $(\mathrm{class} 2) 300,300,201$

201 do 2||$=1, c \mid$ ass 2

$\mathrm{i}=1 \mathrm{i}+1 \mathrm{x}$

$j=i f \mid x((\mathrm{Iu} / v+0.5) * 4)+1$

$f l a g(\mid 1)=s$ tat yp $(2, j)$

2 write $(6,9000) f \operatorname{lag}(i i)$

$11=0$

do $65 j j=1, c$ ass 2

$70 \mid i=1 \|+1$

if $(\mid 1-6) 75,75,77$

75 if (kount $(i i)-\max ) 71,7 n, 70$

77 il $=0$

Eo to 70

71 call limit $(11,1 ! m, 11,12)$

cal 1 plck1 $(11,12, f$ Iag, I ist, Inick, Indct, $j j, \mid u, i x, v)$ $j=$ lplck

if(indct) $76,70,76$

76 if (type 3$) 66,65,67$

671 ist $(j, 2)=1$ in 77952576

type $3=$ type 3-1

knunt $(||)=$ kount $(||)+1$

8n to 65

66 If (type 2) 69,69,68

68 to $63 \mathrm{kk}=3,20$

63 list $(j, k k)=1077952576$

type 2 = type 2-1

kount $(||)=$ kount $(\mid i)+1$

go to 65

69 If (type 1$) 65,65,62$

62 to $61 \mathrm{kk}=1,50$

$61 \mathrm{list}(j, k k)=1077952576$

type 1 = type $1-1$

kount $(||)=$ kount $(||)+1$

65 continue

handle class 1 statements (priorlty to type 3 type 2 type 1 )

300 if (class 1)400,400,301

$3 n 1$ do 3||$=1, c \mid$ ass 1

iugiutix

$j=\mid f i x((i u / v+0.5) * 4)+1$ 
$30 \quad i=1\}+1$

if $(i \mid-6) 35,35,34$

35 if (kount (ii)-max) $31,30,30$

$34 i=0$

go to $3 n$

31 call limit( $|1,1| m, 11, i 2)$

call pickl(11,12,flag, I ist, ipick, indct,jj,iu, $\mid x, v)$ lal ick

if (indet) $36,30,36$

36 if $(f l a g(j j)-s t a t y p(1,4)) 52,29,52$

52 if (type 3$) 26,26,27$

27 I ist $(j, 2)=1077952576$ type $3=$ type $3-1$ kount (ii) akount (ii)+1 80 to 25

If (type 2) 29,29,2s

28 Ho $23 \mathrm{kk}=3,20$

23 list $(j, k k)=1077952576$ type 2 = type $2-1$ kount $(||)$ akount $(||)+1$ go to 25

29 if (type 1) $25,25,22$

22 do $21 k k=1,50$

211 ist $(j, k k)=1077952576$ type $1=$ type $1-1$ kount $(\mid i)=$ knunt $(i \mid)+1$

$$
25 \text { continue }
$$

c see if there is room for phoney ine(s).

Insert phoney IIne(s).

400 if (junk) $99,99,11$

11 to $10 \mid i=1$,junk

$|u=1 u *| x$

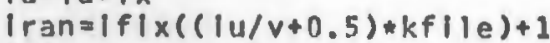

If (kount $($ Iran) $-\max ) 12,10,10$

$12|u=| u * \mid x$

$|\operatorname{ran} 3 \approx| f \mid x((\mid u / v+0.5) * 3)+1$

$1 u=|u *| x$

iran $6=\mid f i x((i u / v+0.5)+10)+1$

call I Imit(Iran, IIm, 11,12)

$j \mathrm{j}=1$

flap(jj)=statyp(1, $\mid \operatorname{ran} 3)$

cal1 pickl(11, I2, flag, | ist, iplck, inde:,jj, iu, ix, v) $j=\mid$ pick

if (indet) $17,10,17$

17 to $18 \quad k k=2,50$

18 IIst $(j, k k)=$ phoney (iran $6, k k-1)$

kount (iran) k kount (iran) 1

10 continue 
1. 0224

1. 0225

I. 0226

1.0227

1. 0223

1.0229

1.0230

1.0231

1.0232

1.0233

1. 0234

.0235

1. 0236

1. 0237

1. 0238

1.0239

1.0240

1.0241

1. 0242

1.0243

1. 0244

1. 0245

1.0246

1. 0247

1. 0248

1.0249

1.0250

1. 0251

1.0252

1.0253

1.0254

1.0255

1. 0256

1.0257

1.0258

1.0259

1.0260

1.0261

put $m$ iscellanecus error in each of the flles

provided tha maximum parameter is not exceeded.

segment of iline is blanked out.

do $50 i j k=i, 2$

do $40 \quad i l=1, k f i l e$

if (kount (ii) -max) $41,40,41$

$41 \mathrm{call} l \mid \mathrm{mit}(1 \mathrm{i}, 1 \mathrm{~m}, 11,12)$

तo $49 j j=11,12$

if( 1 ist $(j j, 2)+958998208) 42,43,42$

42 if $(11$ st $(j j, 2)+n n g 754304) 49,51,49$

43 to $47 k=5,20$

If (i ist $(j j, k)+482328512) 44,47,44$

44 if $(1$ ist $(j j, k)+7 n 0432320) 45,47,45$

45 if $(1$ ist $(j j, k)+499105728) 46,48,46$

46 list $(j j, k)=1077952576$

47 cont inue

48 kount $(1 \mid)=$ kount $(i \mid)+1$

IIst $(j j, k+5)=1077952576$

go to 40

51 in $53 k=3,3 n$

if ( i s t $(j j, k)-2118139968) 54,55,54$

54 If (11st (jj,k) -1279279168$) 56,55,56$

56 if (i ist (jj,k) - 1849704512) 53,55,53

$55115 t(j j, k)=1077952576$

kount $(\mid i)$ kount $(i \mid)+1$

go to 40

53 continue

49 cont inue

40 continue

50 continue

c

programs prepared

99 write $(10,1000)((1 \mid s t(i, j), j-1,50), i=1,135)$

finlshed

stop

end

Iftc

subroutine $1 \mathrm{imlt}(11,1 \mathrm{im}, 11,12)$

dimension $1 \mathrm{im}(10)$

if $(\mid i-1) 2,1,2$

$1 \quad 11=1$

$12=1 \mathrm{im}(i)$

return

$211=1 \operatorname{lm}(\mid i-1)+1$

80 to 3

end 
subrout Ine plckl(11, $12, f|a g|,|s t| p,|c k| n d e t,, j j,|u| x, v$,

1.0265

1.0266

1.0267

1.0268

1.0269

1.0270

1.0271

1.0272

1.0273

1.0274

1.0275

1. 0276

1.0277

1.0278

1.0279

1.0280

1.0281

1.0282

1. 0283

1.0284

dimension keep(10), i ist $(136,50)$

integer flag(10)

$101 \operatorname{keep}(k)=0$

ktotal $=0$

Indet $=$ ?

$i=1$

do $100 j=11,12$

If $(f \mid$ ag $(j j)-11$ st $(j, 2)) 100,102,100$

$102 k e \operatorname{cop}(i)=j$

ktotal ktota $1+1$

$i=i+1$

indict $=1$

100 cont inue

if (Indct) $103,104,103$

$103 i u=i u * i x$

ipick $=i f i x((i u / v+0.5) * k \operatorname{tot} a))+1$

iplck=keep (ipick)

104 return

end

m.0072 begin activity. 
/AIsplay orgpgs

m. 0073 action in progress.

1.0001 /baslc

$1.00022 \mathrm{rem}$

$1.00033 \mathrm{rem}$

$1.0004 \quad 4 \mathrm{rem}$

1.00055 rem

$1.00066 \mathrm{rem}$

$1.00077 \mathrm{rem}$

$1.00088 \mathrm{rem}$

1.00099 rem

1.001010 read $n$

1.001111 Hata 3

1.001212 Input $k$

1.001313 for $i=2$ to $k-1$ step 1

1.001414 if $k / 1=\operatorname{lnt}(k / i)$ then 18

1. 001515 next i

1.0016 16 print k;" is a prime"

1.001717 goto 19

1.0018 $18 \mathrm{print} \mathrm{k:"} \mathrm{is} \mathrm{composite"}$

1.0019 19 let $n=n-1$

1.002020 if $n<>0$ then 12

1.0021 21 ston

1.002222 end

1.0023 /basic

1.00242 rem

$1.00253 \mathrm{rem}$

1.00264 rem

1.00275 rem

$1.00285 \mathrm{rem}$

1.00297 rem

this propram is deslgned to take the square ront of five numbers. program must be able to handle negative and positive numbers.

$1.00308 \mathrm{rem}$ after updating, check results by running

1.00319 rent

using negative and positive data.

$1.0032 \quad 10$ let $n=5$

1.003311 for $i=1$ to $n$ step 1

1.003412 input $k$

1.003513 if $k<0$ then 16

$1.003614 \mathrm{print}$ "the square root of ":k:" is":sqr(k)

1.003715 goto 17

1.0038 $16 \mathrm{print}$ "the square root of ";k;" is";sqr(-k):" "

1.0039 17 next

$1.0040 \quad 18$ ston

$1.0041 \quad 19$ end

1.0042 /basic

1.00432 rem

1.00443 rem

1.00454 rem

1.00465 rem

1.00476 rem

$1.00487 \mathrm{rem}$

$1.00498 \mathrm{rem}$

$1.00509 \mathrm{rem}$

this program is designed to sort the first twelve numbers of an array into ascending order. numbers are read in as data. program should sort the data and print out the results. 


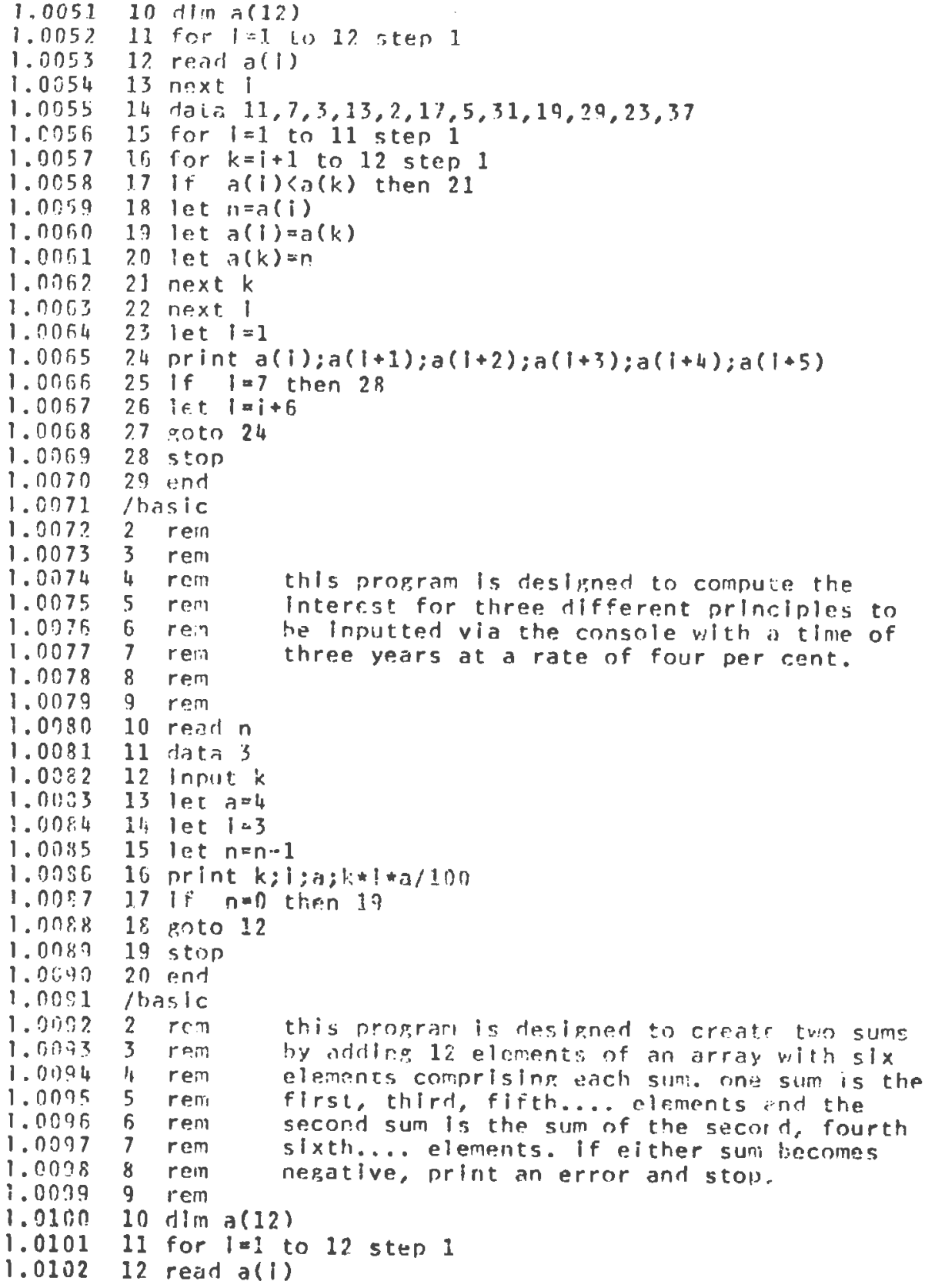


$1.0103 \quad 13$ next 1

1. 0lo: 14 for $i=1$ to 11 sien 2

i. $0105 \quad 15$ let $k=3(i)+k$

$1.0105 \quad 16$ if $k<0$ thesi 23

$1.0107 \quad 17$ let $n=a(i+1)+n$

1.0108 is if $n<0$ then 23

1. 010919 next ।

1.011n 20 print "odd elements ":k;" even elements "in

1.011121 stor

1. 011222 तata $2,4,1,3,0,7,8,-5,-6,11,7,-10$

1.011323 print "negative sum encounterét"

1.011424 goto 21

1.011525 end

1.01:E /haric

1.01172 ,em

1.01183 ren

1.0119 is rem

$1.0120 \quad 5$ rem

this program is deslrned to create the flrst

1.01227 rem

two start values, each number is gotten by

1.01238 rem

1.0124 a rem

1. 0125 in $\operatorname{let} n(1)=0$

1.0125 l. let $n ! n)=1$

1.012712 for $i=3$ to 10 step 1

$1.012 .8 \quad 13$ iet $n(i)=n(i-1)+n(i-2)$

$1.0129 \quad 14$ next i

$1.0130 \quad 15$ let $k=1$

1.0131 15 print $n(k)$

1.013? 17 if $k=10$ then 20

$1.0133 \quad 18 \quad l \in t \quad k=k+1$

$1.0 ? 3419$ goto 16

1.013520 stap

1.013621 end

m.0072 begin activity. 
m.0073 action in progress.

m.0070 action complete.

lend

m.0072 begin activity.

lupdate

/Alsplay

m. 0073 action In progress.

1.0001/baslc

1.00022 rem

$1.00033 \mathrm{ram}$

1.0004 4 rem

$1.00055 \mathrm{rem}$

1.00066 rem

1.00077 rem

this program is designed to take the square

$1.0008 \quad 8$ rem

root of five numbers. propram must be able

1.0000 s rem

to handle negative and posicive numbers.

1.00099 rem

1. $0010 \quad 10$ let $n=5$

1.001111 for

1.0012

$1.0013 \quad 13$ if $k<0$ then 1 \%

.001414 print "the square root of "ik:" is";sqr(k)

1.001515 goto 17

1.0016 $16 \mathrm{print}$ "the square root of ";k:" Is":sar(-k):" |"

$1.0017 \quad 17$ next

1.001818 ston

1.0019 19 end

1.0020 lend

/change 11,12

11 for $l=1$ to $n$ step 1

12 Input $k$

/end

m.0073 action in progres5.

update successfully completed

m. 0072 begin activity.

/ run

$m .0073$ action in progress.

** diagnostics ***

no statements flagged in this complle

$=25$

the square root of -25

32

the square root of 32

16

the square root of 16

$=16$

the square root of -16

o

the square root of 0

is 5

m. 0072 begin activity.

Is 5.65685

Is 4

is 4

is 0 


\section{Input}

linsert exam4z

m. 0073 action in progress.

m.n070 action complete.

lend

m. 0072 begin activity.

/update

/Aisplay

m. 0073 action in progress.

1.0001 /basic

1.00022 rem

..0002 2 rem

$1.0003 \quad 3$ rem

1.00055 rem

$1.0006 \quad 6$ rem

1.00077 rem

$1.0008 \quad 8$ rem

$1.00099 \mathrm{rem}$

1.0010 10 let $n=5$

1.001111 for $1=$ to sten

1.001212 input $k$

$1.0013 \quad 13$ if $k<n$ then 16

1.0014

1.0015

15 goto 14

1.0016

1.0017 17 next ।

1.001818 stop

1. $0019 \quad 19$ end

1.0020 /end

/change 11,11

11 for $i=1$ to $n$ step 1

/ change 14,15

14 print "the square root of "; $k$;" is "isqr(k)

15 goto 17

/change $16, \$ 6$

16 print "the square root of "jk;" is ";sqr(-k):"i"

lend

m.0073 action in progress.

update successfully completed

m. 0072 begin activity.

Irun

m.0073 action in progress.

** dlagnostlcs .*

no statements flagged in this complle

32

the square root of 32

$=25$

the square root of -25

is 5.65685

25

the square root of 25

Is 5

100

the square ront of 100

is 5

is 10

the square root of 0

m. 0072 begin activity. 
Iinsert exam26

m.0073 action in progress.

m.0070 action completr.

lent

m.0072 begin activity.

lupdate

/Alsplay

m. 0073 action in progress.

1.0001 /basic

$1.00022 \mathrm{rem}$

$1.00033 \mathrm{rem}$

$1.0004 \quad 4 \mathrm{rem}$

$1.00055 \mathrm{rem}$

1.00056 rem

1.00077 rem

this prograin is desizned to creote the first

ten numbers of the fibonaccl seauence. given

1.0008 o rem

1.0009 g rem

1.0010 in let $n(1)=0$

1.0011 11 let $n(2)=1$

1. Di112 12 for $i=$ to step

$1.0013 \quad 13$ let $n(1)=n(1-1)+n(1-2)$

1.001414 next i

$1.0015 \quad 15$ let $k=1$

1.001516 print $n(k)$

1.0017

$1.0018 \quad 18$ let $k=k+1$

1.001919 goto 16

1.002020 stop

1.002121 end

1.0022 lent

/change 12,12

12. for $i=3$ to 10 step 1

/change 17,17

17 if $k=10$ then 20

\section{/end}

m.0073 action in progress.

update successfully completed

m. 0072 begin activity.

Irun

m. 0073 action in progress.

*** diagnostics *\#*

no statements flagerd in thls complie 
m.0073 action in progress.

m. $0117 n$ action complete.

lend

m. 0172 begin activity.

/update

/display

m.0073 action in progress.

1. 0c01 /hasic

1.00022 rem

$1.00033 \mathrm{rem}$

$1.0004 \quad 4$ rem

1.00055 rem

1.00066 rem

this program is designed to create the first

1.00077 rem

ten numbers of the fibonacel seauence. Eiven

two start values, each number is gotten by

$1.00088 \mathrm{rem}$

$1.00099 \mathrm{rem}$

1.0010 in coto 13

1.0011 11 let $n(2)=1$

1.001212 for $1=3$ to 10 step 1

$1.0013 \quad 13$ let $n(1)=n(1-1)+n(1-2)$

1.001414 next

1. 0015 is let $k=1$

$1.001616 \mathrm{prlnt} n(\mathrm{k})$

1.0017

$1.0018 \quad 18$ let $k m k+1$

1.0019 ig if $i<0$ then 13

1.002020 stop

1. 002121 end

1.0022 /end

/change 14,14

14 next i

/change 17,17

17 if $k=10$ then 20

/change 19,19

19 goto 16

lend

$\mathrm{m}, 0073$ action in progress.

update successfully completed

m.0072 begin activity.

Irun

m.0073 action in propress.

*.* dlaznostles **

no statements flagged in this complle

error 304

m.0072 begIn activity.

/uprate

/change 10,10

10 let $n(I)=0$

lend

m.0073 action in prozress.

update successfully completed

m. 0072 begin activity. 
r run

m. 0073 action in prozress.

$* *$ diagnostics $\# *$

no statements flagged in this complin

1

2

5

13

21

m. 0072 begin activity. 
APPEXIX E

PROGRAH TO SHPARATE PREPARED UNSOIVED PROBLEHS 
Aisplay slice

m.0073 action in propress.

$1.0001 / f+c$

$1.01002 \mathrm{c}$

$1.0003 \mathrm{c}$

1.0005

1.0006

1.0007

1.0008

1.0009

1.0010

1.0011

1. 0012

1.0013

1.0014

$1.0015 /$ tat

m. 0072 begin activity.

dinension $x(136,25)$

$\operatorname{read}(5,1 ; 00) i(j(i, j), j=1,25), i=1,136)$

1000 format $(25 \pi 3)$

write $(6,30 n n)$

$30 n 0$ forinat ('type in $11 \mathrm{mits}$ ')

read $(9,2000) 11,12$

2000 format $(213)$

write $(10,1000)((a(i, j), j=1,25), i=11,1:)$

ston 